Emília Aparecida Valinetti

\title{
Efeito da bupivacaína racêmica e da mistura enantiomérica de bupivacaína associadas ou não com a clonidina, para anestesia caudal em crianças
}

Tese apresentada à Faculdade de Medicina da Universidade de São Paulo para obtenção do título de Doutor em Ciências.

Área de Concentração: Anestesiologia

Orientador: Prof. Dr. Irimar de Paula Posso 
Emília Aparecida Valinetti

\section{Efeito da bupivacaína racêmica e da mistura enantiomérica de bupivacaína associadas ou não com a clonidina, para anestesia caudal em crianças}

Tese apresentada à Faculdade de Medicina da Universidade de São Paulo para obtenção do título de Doutor em Ciências.

Área de Concentração: Anestesiologia

Orientador: Prof. Dr. Irimar de Paula Posso 


\section{NORMALIZAÇÃO ADOTADA}

Esta tese de doutorado está de acordo com:

Referências: adaptado de International Committee of Medical Journals Editors (Vancouver), onde adotamos o sistema autor - data para as citações dos documentos no texto, e as referências bibliográficas foram ordenadas alfabeticamente.

Universidade de São Paulo. Faculdade de Medicina. Serviço de Biblioteca e Documentação. Guia de apresentação de dissertações, teses e monografias. Elaborado por Anneliese Carneiro da Cunha, Maria Júlia de A L Freddi, Maria F Crestana, Marinalva de Souza Aragão, Suely Campos Cardoso, Valéria Vilhena. São Paulo: Serviço de Biblioteca e Documentação; 2004.

Abreviaturas dos títulos dos periódicos de acordo com List of Journals Indexed in Index Medicus. 
Aos meus pais (in memoriam)

Todo meu amor e gratidão.

Ao meu filho

Meu orgulho, meu norte, que caminha do meu lado e conhece todos meus motivos. Para você com amor e delicadeza. 


\section{AGRADECIMENTOS}

Ao Gustavo, a força motriz, a pedra fundamental.

Professor Dr. José Otávio Costa Auler Jr. pelo incentivo e apoio, certamente um exemplo de dedicação.

Professor Dr. Irimar de Paula Posso pela dedicada e delicada orientação.

Professor Dr. João Gilberto Maksoud e Professor Dr. Uenis Tannuri pelo apoio e pelo exemplo de dedicação.

Toda equipe da Cirurgia Pediátrica do ICr HC-FMUSP: Dr. Arthur L. Mathias, Dra. Mercês Santos, Dr. Marcos Silva, Dr. João Gilberto Maksoud Filho, Dr. Ali Ayoubi, Dra. Maria Lúcia Pinho, Dr. Nelson Gibelli, Dr. Wagner Andrade.

Dr. Manoel Carlos Prieto Velhote porque é um espelho de garra e tenacidade.

Doutores Ana Cristina A. Tannuri, Rodrigo L. Romão e Norio Matsumara.

Gilvam Vila Nova Gomes e Dra. Cleide Harue Maluvayshi do Setor de Farmácia do ICr HC-FMUSP pela seriedade que conduziram identificação e preparação das soluções estudadas.

Instituto da Criança HC-FMUSP que apoiou a realização deste estudo.

Mariane Cury pela realização do tratamento estatístico.

Enfermagem do Centro Cirúrgico: Ana Maria Andrade, Rose Keiko ("Rose-Bombom”), Ritinha, Pedrina, Clarice, Renata.

Enfermagem da Cirurgia Pediátrica (enfermaria): Mitchiko, Suzana, Haline, Jane, Conceição, Damaris e todas as enfermeiras e auxiliares.

A todas as auxiliares da enfermagem do Centro Cirúrgico: Esther, Dulcinéia ("Neguinha”), Dulcinéia (D. Dulce), Adriana ("Drica”), Renata, Patrícia ("Pati”), Margarida (“Meg”), Ivonilda, Paulo, Andréa.

Para as secretárias: Ana Maria lazetti (Aninha), Patrícia, Selminha.

Aos pais e crianças que participaram do estudo.

Aos pós-graduandos da Disciplina de Anestesiologia da FMUSP. 
Para as secretárias do programa de pós-graduação da Disciplina de Anestesiologia FMUSP: Solange e Gisele.

Aos médicos colaboradores do ICr HC-FMUSP: Dra. Cláudia Marques Simões e Maria Fernanda Bertachi.

Para Dr. André Schmidt, médico preceptor da anestesiologia, pela gentileza ímpar na correção do inglês durante a fase final do estudo.

Para Fernanda Maluf Saad Haddad pela pontual supervisão do inglês, para a versão do resumo.

Para o time de anestesiologistas do ICr HC-FMUSP: Dra. Anna M. Falchetto, Dra. Márcia M. Gonçalves, Dr. Hiroshi Ohira, Dra. Cristiane V. Caratim, Dra. Massako Ichimura, Dra. Kátia Y. Yamamoto de Souza, Dr. Marcelo de Carvalho, Dra. Leila A. Ferrari, Dr. Ricardo V. Carlos, Dra. Charlize Kessin Oliveira Sales, Dra. Carla Marília N. Magalhães, Dra. Suzana Pereira Miranda Teruya, Dra. Rosana Machado Santos Jacob.

Dra. Simonetti e Dra. Dorothy Nigro pelo apoio e incentivo.

Dra. Carmen Narvaes Bello pela correção e sugestões pontuais.

Aos demais membros da banca do exame de qualificação: Dra. Mônica S. Cardoso, Dra. Márcia Pavan de Andrade, Dr. Hazem Adel Ashmawi pelas sugestões.

Dr. Arnaldo Zanotto que na década de 90 me apoiou e incentivou a realização do Mestrado.

Laboratório Cristália pelo fornecimento dos fármacos para o estudo (S75R25, SR50 e Clonidina).

Aos amigos muito presentes e aos que por motivos geográficos estão distantes.

Todos que de alguma maneira colaboraram para que este estudo fosse concluído. 


\section{SUMÁRIO}

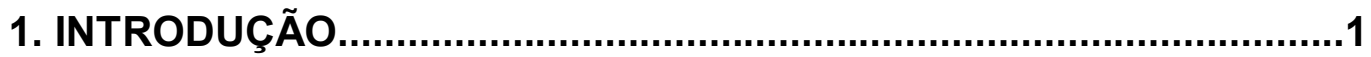

1.1. Aspectos químicos, princípios gerais da quiralidade ....................

1.2. Bupivacaína: Um anestésico local com carbono assimétrico.....3

1.3. Clonidina..................................................................................................6

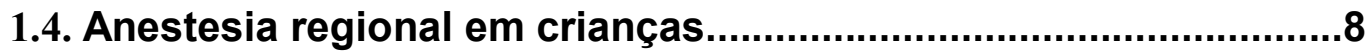

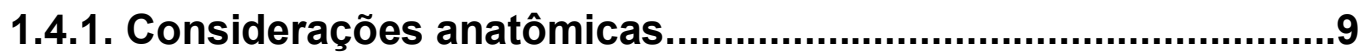

1.4.2.Considerações farmacocinéticas e farmacodinâmicas.............10

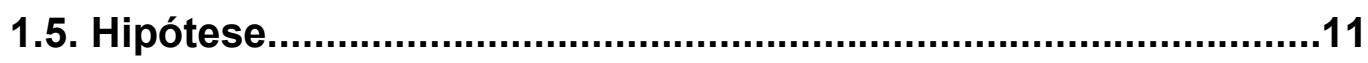

2. OBJETIVOS

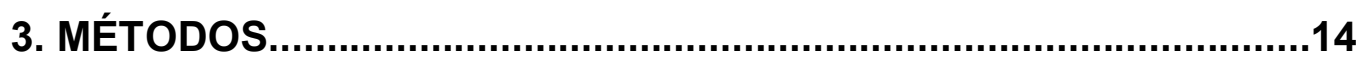

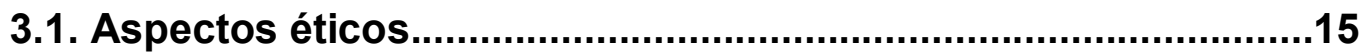

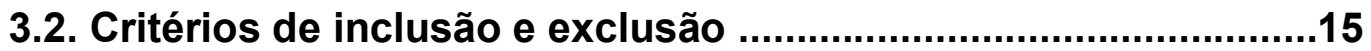

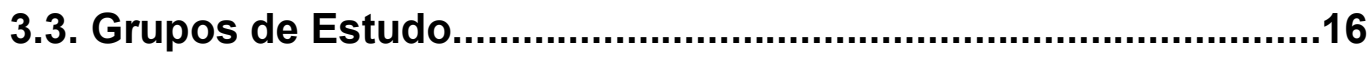

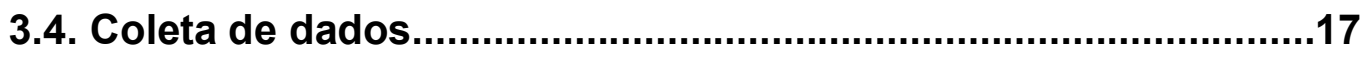

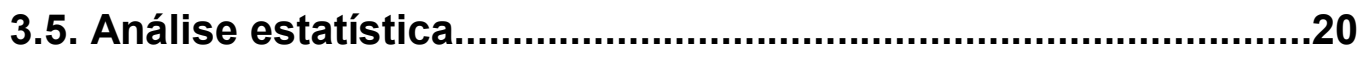

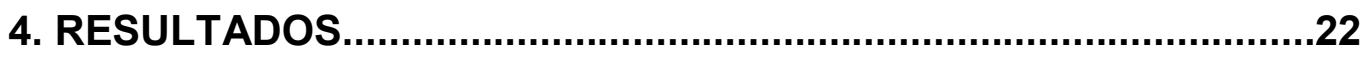

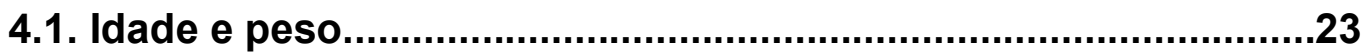

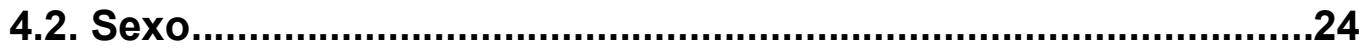

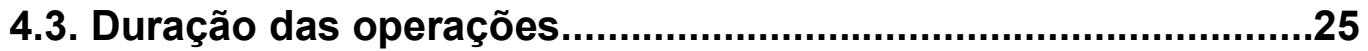

4.4. Intervalo entre a realização do bloqueio e início da operação..26

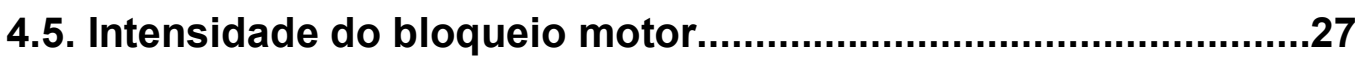

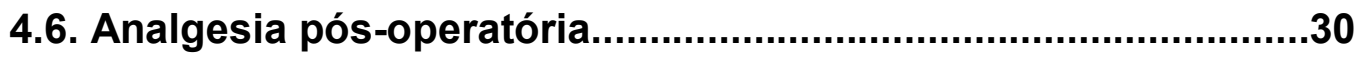

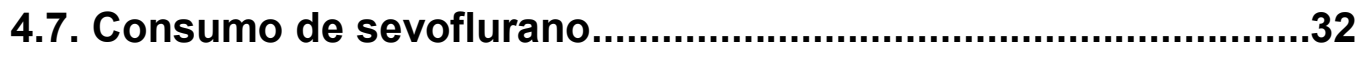

4.8. Intervalo entre punção sacral e primeira dose de analgésico...34

4.9. Consumo de analgésico na residência.......................................36

4.10. Consumo de fentanil durante a anestesia................................37

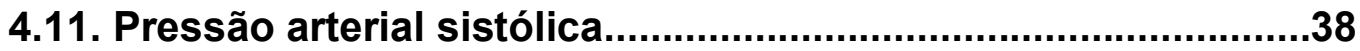

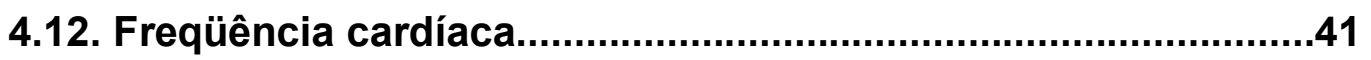

4.13. Saturação periférica de oxigênio..............................................44

4.14. Fração expirada de dióxido de carbono....................................46 


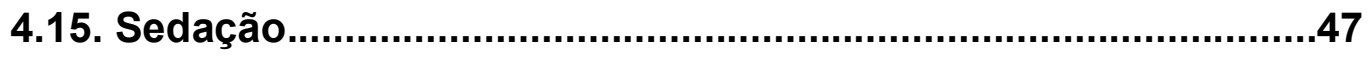

4.16. Eventos adversos....................................................................48

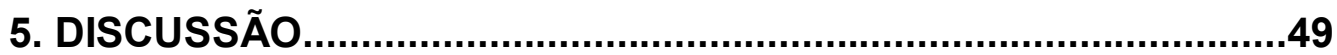

5.1. Limitações do estudo...........................................................51

5.2. Considerações sobre bloqueio motor e analgesia...................54

5.3. Clonidina e consumo de sevoflurano.......................................60

5.4. Eventos adversos................................................................61

5.5. Considerações sobre as variáveis hemodinâmicas no perioperatório......61

5.6. Considerações finais............................................................62

6. CONCLUSÕES.............................................................................64

7. REFERÊNCIAS BIBLIOGRÁFICAS............................................66

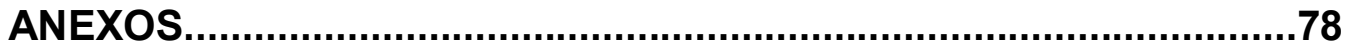

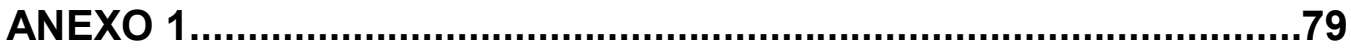

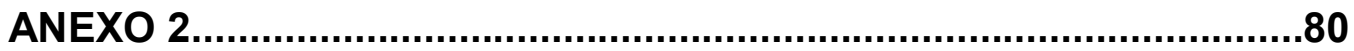

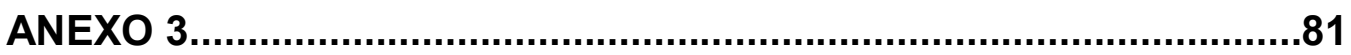

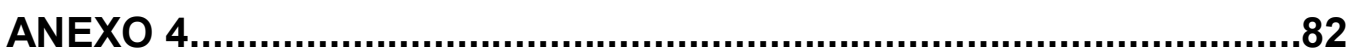

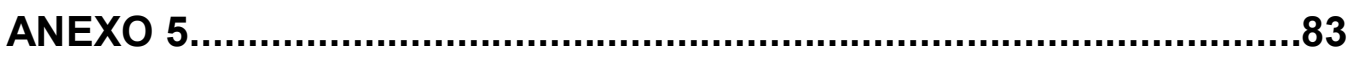

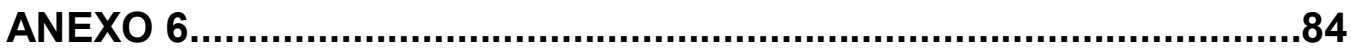




\section{LISTA DE FIGURAS}

Figura 1 - Intensidade do bloqueio motor ...........................................28

Figura 2 - Analgesia no pós-operatório ……………………………......31

Figura 3 - Consumo de sevoflurano ...................................................33

Figura 4 - Intervalo entre a punção sacral e a primeira dose analgésico................35

Figura 5 - Pressão arterial sistólica do início até o primeiro minuto após a intubação traqueal

Figura 6 - Pressão arterial sistólica a cada 5 minutos durante o procedimento

Figura 7 - Pressão arterial sistólica no período pós-operatório .40

Figura 8 - Freqüência cardíaca ate intubação traqueal

Figura 9 - Freqüência cardíaca a cada 5 minutos durante 0 procedimento

Figura 10 - Freqüência cardíaca no período pós-operatório. .43

Figura 11 - Saturação de oxigênio até a intubação traqueal .44

Figura 12 - Saturação de oxigênio a cada 5 minutos durante 0 procedimento 45

Figura 13 - Fração expirada de dióxido de carbono após intubação traqueal durante o procedimento. .46

Figura 14 - Sedação no pós-operatório 


\section{LISTA DE TABELAS}

Tabela 1 - Distribuição das crianças estudadas de acordo com idade e peso .23

Tabela 2 - Distribuição das crianças estudadas de acordo com o sexo

Tabela 3 - Distribuição das crianças estudadas de acordo com o tipo de cirurgia 24

Tabela 4 - Duração dos procedimentos nos grupos estudados....25 Tabela 5 - Tempo em minutos entre a realização do bloqueio e a incisão da pele 26

Tabela 6 - Intensidade do bloqueio motor 27 Tabela 7 - Comparação do bloqueio motor nos momentos de avaliação.

Tabela 8 - Comparação entre a intensidade do bloqueio motor entre os grupos e os momentos estudados 29

Tabela 9 - Analgesia no pós-operatório avaliada pela escala objetiva de avaliação da dor (OPS) 30

Tabela 10 - Consumo de sevoflurano até intubação traqueal e após a intubação traqueal 32

Tabela 11 - Comparação do consumo de sevoflurano entre os grupos e momentos estudados .33

Tabela 12 - Intervalo entre a realização do bloqueio epidural e a primeira dose de analgésico em minutos .34

Tabela 13 - Pacientes que usaram analgésico na residência 36

Tabela 14 - Número de doses de analgésico usados na residência. .36

Tabela 15 - Necessidade de fentanil durante a anestesia 37

Tabela 16 - Fração expirada de dióxido de carbono em $\mathrm{mmHg}$ avaliada após a intubação traqueal durante o estudo .46

Tabela 17 - Alterações respiratórias, náuseas e vômitos 


\section{LISTA DE ABREVIATURAS, SÍMBOLOS E SIGLAS}

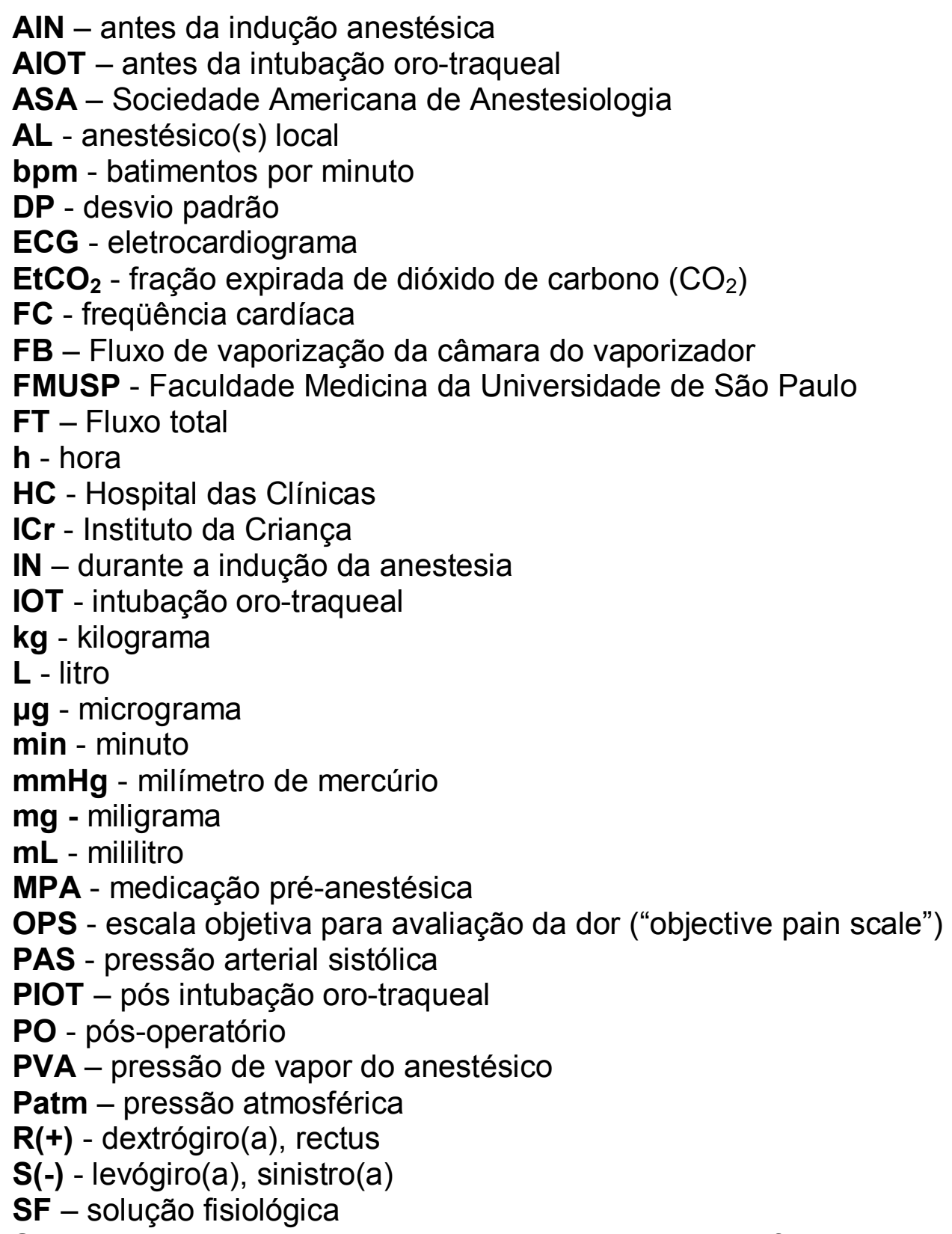

S75R25 _ mistura enantiomérica de bupivacaína em diferente proporção, $75 \%$ de $\bar{S}(-)$ e $25 \%$ de $R(+)$

SR50_ mistura racêmica da bupivacaína

SRPA - sala de recuperação pós-anestésica

$\mathrm{SpO}_{2}$ - saturação periférica de oxigênio $\left(\mathrm{O}_{2}\right)$ 


\section{RESUMO}

Valinetti EA - Efeito da bupivacaína racêmica e da mistura enantiomérica de bupivacaína associadas ou não com a clonidina, para anestesia caudal em crianças [tese]. São Paulo: Faculdade de Medicina, Universidade de São Paulo; 2005, 86p.

Este é um estudo clínico, prospectivo, aleatório, e duplamente encoberto realizado em 40 crianças submetidas a cirurgia infra-umbilical de pequeno porte, sob anestesia epidural sacra realizada com a mistura enantiomérica de bupivacaína (S75R25) comparada com a bupivacaína racêmica (SR50) isoladas ou em associação com a clonidina. O objetivo foi avaliar a duração do bloqueio motor e sensitivo, o consumo de sevoflurano e as variações da pressão arterial sistólica (PAS) e freqüência cardíaca (FC). O bloqueio motor foi avaliado pela escala de Bromage, durante o período de oito horas de observação no pós-operatório. A analgesia foi avaliada pelos escores obtidos com escala objetiva para análise da dor e a duração da analgesia foi considerada como o tempo entre a administração do anestésico local no espaço epidural sacro e a primeira dose de analgésico administrado. Os resultados obtidos foram submetidos à análise estatística onde $p<0,05$ foi considerado significante. Os resultados mostraram que houve aumento significativo do bloqueio motor somente na primeira hora quando a bupivacaína SR50 foi associada a clonidina, mas não ocorreu o mesmo com a bupivacaína S75R25. Em relação a analgesia não houve diferença significante entre a bupivacaína SR50 e a bupivacaína S75R25 associadas ou não à clonidina. Não houve diferença significativa no consumo de sevoflurano entre os grupos estudados quando a clonidina foi associada aos anestésicos. Os valores da PAS e FC no pós-operatório, nos grupos onde a clonidina foi associada com ambos anestésicos locais, foram inferiores em todos os momentos de avaliação, porém sem significância estatística.

Descritores: 1. BUPIVACAÍNA/efeitos adversos 2. CLONIDINA/agonistas 3. ADJUVANTES ANESTÉSICOS/ agonistas 4.ANESTESIA CAUDAL/métodos 5. ANESTESIA E ANALGESIA 6. CRIANÇA. 


\section{SUMMARY}

Valinetti EA - Effect of racemic bupivacaine and enantiomeric mixture of bupivacaine associated or not with clonidine on caudal anesthesia in children [thesis]. São Paulo, Faculdade de Medicina, Universidade de São Paulo; 2005, 86p.

This is a prospective, randomized double-blind clinical trial performed in 40 children using an enantiomeric mixture of bupivacaine (S75R25) compared to racemic bupivacaine SR50 plain or associated with clonidine, to caudal blockade. The aim of this study was to investigate the motor and sensitive block, sevoflurane requirement, blood pressure (PAS) and heart rate (FC) in children scheduled to sub-umbelical surgeries. The motor block was evaluated by Bromage scale for eight hours during the postoperative period. The analgesia was evaluated postoperatively for eight hours by an objective pain scale and the analgesia duration was taken as the time between the local anesthetic administration into epidural space and the first analgesic rescue. The results obtained were submitted to statistical analysis test where $p<0,05$ was considered significant. There was a significant increase in the motor block at first hour on postoperative period when bupivacaine SR50 was associated to clonidine, but it did not occurr with the enantiomeric mixture of bupivacaine S75R25. There was no difference between bupivacaine SR50 and bupivacaine S75R25 associated or not to clonidine regarding to analgesia duration. There was no difference in the requirement of sevoflurane between groups in spite of the clonidine admixture to the local anesthetics. There was an absolut decrease in the PAS and FC values on the postoperative evaluation, but it was not statistically significant. Descriptors: 1. BUPIVACAINE/ adverse effects 2. CLONIDINE/agonists 3. ANESTHETICS ADUVANTS/agonists 4. CAUDAL BLOCKADE/methods 5. ANESTHESIA AND ANALGESIA 6. CHILD. 
1. INTRODUÇÃO 


\subsection{Aspectos químicos e princípios gerais da quiralidade}

A molécula de um composto químico contém diferentes tipos de átomos. Isômeros são compostos com a mesma fórmula molecular, mas com estrutura molecular diferente. Os estereoisômeros apresentam idêntico arranjo de ligações conectando seus átomos, contudo, a orientação espacial dos átomos difere. Enantiômeros são pares de estereoisômeros que em sua projeção tridimensional estão relacionados como uma imagem especular, portanto não se sobrepõem e são chamados compostos quirais (Nau e Strichartz, 2002).

Desta forma, é possível a formação de dois arranjos espaciais da molécula se colocada frente ao espelho. Os isômeros formados são denominados de $\mathrm{R}$ (rectus) quando a direção da rotação se faz da esquerda para a direita a partir do radical ligado ao carbono assimétrico com maior peso molecular, ou é denominado $S$ (sinistrum) quando a sua imagem especular apresenta a mesma rotação, porém da direita para a esquerda em relação ao mesmo radical citado anteriormente. Esta nomenclatura para descrever a disposição espacial dos estereoisômeros foi proposta por CahnPrelog-Ingold (Cahn et al., 1956).

Outro método para se referir a quiralidade da molécula se relaciona ao sentido da rotação do plano de luz polarizada, ou no sentido horário (+) ou anti-horário (-). $\mathrm{Na}$ realidade, os estereoisômeros são descritos por uma combinação de ambos os métodos para sua identificação gráfica, S(-) bupivacaína, por exemplo.

Estes enantiômeros (enantios de origem grega significa contrário) são ditos opticamente ativos, porque desviam a luz em direção oposta ao carbono assimétrico. Assim sendo, uma solução aquosa contendo somente 
número par de estereisômeros, mistura racêmica, não causa rotação do plano da luz polarizada ao passar através da mesma. Entretanto, quando a solução possui diferente quantidade de enantiômeros o desvio do plano da luz se faz de acordo com o enantiômero predominante na solução. É importante salientar que os enantiômeros possuem as propriedades físicoquímicas idênticas às da mistura racêmica.

A maioria das respostas farmacológica é mediada por receptores, cuja especificidade de resposta é garantida pelo reconhecimento da molécula do agente pelo receptor. De um modo geral, drogas que se ligam ao receptor alvo com alta afinidade, são também drogas que apresentam grande estereoseletividade.

A síntese em escala industrial de estereoisômeros puros ou em diferente proporção como a levobupivacaína e a mistura enantiomérica de bupivacaína permitiu que estes fármacos mantivessem o mesmo perfil farmacodinâmico sobre os receptores e tecidos alvos, porém com abolição ou atenuação de efeitos adversos devidos a sua formulação racêmica. Além disso, o organismo é poupado da metabolização e excreção de um segundo composto presente na composição da mistura racêmica.

\subsection{Bupivacaína: Um anestésico local com carbono assimétrico}

O anestésico local bupivacaína é muito utilizado clinicamente por ser potente e de longa duração de ação. A sua potencial toxicidade para o sistema nervoso central e cardiovascular estimulou a pesquisa de novos anestésicos locais mais seguros. A toxicidade sistêmica que a bupivacaína racêmica (SR50) possui, especialmente quando da injeção inadvertida em vaso sanguíneo, é atribuída ao isômero $R(+)$. O isômero $R(+)$ apresenta características diferentes de ocupação do canal de sódio, receptor do anestésico local, tornando mais lenta a dissociação da molécula do mesmo 
no receptor do sistema nervoso central e cardíaco. Esta característica de ligação rápida e dissociação lenta, somada ao fato dos canais de sódio serem sensíveis à variação da freqüência de estímulo, confere a bupivacaína um padrão de bloqueio cumulativo (Freid et al., 1993).

A ropivacaína e a levobupivacaína, são isômeros $S(-)$ de anestésicos locais, e são menos tóxicos que a bupivacaína racêmica (Nau e Strichartz, 2002). A mistura enantiomérica de bupivacaína (S75R25) é o resultado da pesquisa por um anestésico local que apresentasse características de bloqueio neural de longa duração, mas com menor toxicidade sistêmica. Ferreira (1999) utilizando nervo ciático de rato como modelo experimental, comprovou que a S75R25 mantem as propriedades anestésicas locais da SR50. Posteriormente, Simonetti et al. (2000) demonstraram em ratos que a S75R25 em bolus intravenoso possui menor cardiotoxicidade que a SR50, atribuindo este efeito à diminuição do isômero $R(+)$ na composição do novo fármaco.

O principal alvo molecular dos anestésicos locais é o canal de sódio voltagem-dependente das membranas excitáveis, que controlam a permeabilidade dos íons sódio através das mesmas (Butterworth e Strichartz, 1990 e 1993). A ligação dos anestésicos locais ao canal de sódio impede a geração e a propagação do potencial de ação. Esta ligação é dependente do potencial da membrana e do padrão de despolarização, indicando que a ligação é modulada pelo estado de conformação dos canais de sódio. Os canais de sódio em conformação aberta e particularmente inativados apresentam maior afinidade pelo anestésico local, que em conformação de repouso.

Alguns tipos de canal de sódio, como o neuronal e o cardíaco, têm sido estudados em relação a estereoseletividade dos enantiômeros da bupivacaína. Parece ser fraca ou moderada a estereoseletividade desses canais de sódio para 0 enantiômero $\mathrm{S}(-)$ da bupivacaína. A 
estereoseletividade parece também ser influenciada pelo estado conformacional do canal de sódio. O isômero $R(+)$ da bupivacaína exibe potência em torno de 1,5 vez maior para o estado inativado do canal de sódio, quando comparado com o seu isômero S(-). (Valenzuela et al., 1995).

A fraca estereoseletividade da bupivacaína $\mathrm{S}(-)$ foi demonstrada em estudos experimentais, in vitro e in vivo, que investigaram as diferenças estereoseletivas deste agente no bloqueio neural. Brau et al. (2000) comprovaram que a ropivacaína (um enantiômero $S$ puro) é menos potente que a levobupivacaína ou a bupivacaína racêmica no bloqueio dos canais de sódio.

Kopacz et al. (2000) compararam a ação anestésica e analgésica da levobupivacaína e bupivacaína racêmica na anestesia peridural em adultos e não observaram diferença significativa entre os agentes, porém o bloqueio sensitivo foi mais longo com a levobupivacaína, embora sem significância estatística.

Em estudo experimental realizado em ovelhas, para investigar a toxicidade sistêmica foi comprovado que a bupivacaína $R(+)$ apresenta $50 \%$ mais efeitos tóxicos sistêmicos quando comparada à S(-). Estes efeitos tóxicos foram atribuídos a cardiotoxicidade, devido a efeito direto ou indireto ou ambos sobre o miocárdio, mediados centralmente e à toxicidade sobre o sistema nervoso central (Huang et al., 1998).

Colapso cardiovascular em cães induzido pela administração intravenosa de anestésicos locais demonstrou que a ressuscitação dos animais foi mais prontamente obtida quando se usou a levobupivacaína do que a bupivacaína SR50. Nesse estudo, a ressuscitação dos cães foi mais bem sucedida com a ropivacaína comparada a bupivacaína SR50 e a levobupivacaína (Groban et al., 2001). 
A diferença na cardiotoxicidade da bupivacaína e ropivacaína foi atribuída às propriedades físico-químicas e estereoseletivas diferentes entre esses anestésicos locais (Graf et al., 2002). A substituição por um radical butil no núcleo pipecolil-xilidina confere maior estereoseletividade e cardiotoxicidade para a levobupivacaína quando comparada a ropivacaína. Estes autores observaram que o efeito sobre a condução átrio ventricular e a freqüência cardíaca em coração isolado de camundongos, foi dosedependente.

Recentemente, novas técnicas foram desenvolvidas e possibilitaram a separação destes dois isômeros a partir da solução racêmica da bupivacaína. Este avanço tecnológico estimulou o crescente interesse na investigação da propriedade anestésica local da levobupivacaína. Após a realização de estudos experimentais (Valenzuela et al., 1995; Simonetti e Fernandes, 1997; Simonetti et al., 1997b; Huang et al., 1998; Brau et al., 2000; Groban et al., 2001) e clínico (Kopacz et al., 2000), os autores comprovaram que a levobupivacaína e a bupivacaína S75R25 mantém a propriedade anestésica local, porém, com menor toxicidade sistêmica quando comparada à mistura racêmica.

\subsection{Clonidina}

Para prolongar o bloqueio sensitivo produzido pelos anestésicos locais, alguns adjuvantes são acrescentados aos mesmos. Os mais freqüentemente utilizados são: vasoconstritores (adrenalina), opióides (morfina, fentanil, sufentanil), antagonistas dos receptores NMDA (cetamina) e agonista $\alpha_{2}$ adrenérgico (clonidina). (Cook et al., 1995; Rice, 1996; Motsch et al., 1997; Krane, 1988; Nishina et al., 1999). Apesar dos opióides proporcionarem melhor qualidade de analgesia, eles apresentam como desvantagem o prurido, a náusea, a retenção urinária e a depressão respiratória no pós-operatório (Rice, 1996; Nishina et al., 1999). 
A clonidina é um agonista parcial de alfa-adrenoceptores sendo mais seletiva para os receptores $\alpha_{2}$ do que para $\alpha_{1}$, em proporção de 200:1. Inicialmente a clonidina foi utilizada como descongestionante nasal, devido às suas propriedades vasoconstritoras. Durante os ensaios clínicos houve um caso de superdosagem com o aparecimento de efeitos sedativos, hipotensores e bradicardizantes após a sua utilização pela via nasal (Hoefke, 1980).

Os efeitos colaterais dessa superdosagem foram responsáveis pela introdução da clonidina como anti-hipertensivo em adultos em 1966 (Hoefke, 1980). Pacientes que faziam uso da clonidina como antihipertensivo e foram submetidos à cirurgia cardíaca apresentaram estabilidade cardiovascular, atenuação dos efeitos indesejáveis decorrentes da laringoscopia, diminuição do consumo de anestésicos no intra-operatório e de fenômenos isquêmicos no pós-operatório (Flacke et al., 1987).

Estas observações foram responsáveis pela introdução da clonidina como adjuvante na anestesia de pacientes adultos durante a década de 80 , enquanto que em pacientes pediátricos o uso somente ocorreu na década de 90 (Nishina et al., 1999).

A ativação de receptores $\alpha_{2}$ adrenérgicos no tronco cerebral pela clonidina devido a sua ação agonista, promove analgesia por ativação das vias inibitórias descendentes noradrenérgicas, além da inibição da liberação de neurotransmissores central e perifericamente (Kamibayashi e Maze, 2000)

Butterworth e Strichartz (1993) demonstraram em nervo ciático, in vitro, que a clonidina diminui a velocidade de condução do impulso nervoso principalmente nas fibras Aঠ e C. Essas fibras são responsáveis pela condução do impulso nociceptivo. 
A analgesia promovida pela clonidina parece envolver também o sistema colinérgico na medula espinhal, já que a acetilcolina demonstrou efeito de potencialização da analgesia com diminuição dos efeitos da clonidina sobre a redução da pressão sanguínea (Klimscha et al., 1997).

Quando a clonidina foi associada a anestésicos locais em nervo ciático de rato, in vivo, observou-se aumento da duração do bloqueio sensitivo e motor e diminuição da latência da bupivacaína. A diminuição da latência da bupivacaína parece estar relacionada a alta dose de clonidina utilizada no estudo (Valinetti, 1995).

A associação de clonidina a anestésicos locais promove aumento da duração do bloqueio sensitivo, permitindo a redução da massa total do anestésico local utilizado para a anestesia regional. Além disso, prolonga a analgesia no pós-operatório, reduz o consumo de fármacos anestésicos no perioperatório e a necessidade de analgésicos no pósoperatório (Klamt et al.. 2003). Kulka et al., (2001) comprovaram que a clonidina administrada por via venosa após a indução com sevoflurano preveniu a agitação no pós-operatório imediato sem aumento da incidência de efeitos adversos. A sua vantagem principal consiste em não induzir prurido, retenção urinária e depressão respiratória no pós-operatório (Cook et al., 1995; Rice, 1996; Motsch et al., 1997; Nishina et al., 1999).

\subsection{Anestesia regional em crianças}

A peridural sacra é uma técnica de anestesia regional consagrada em pacientes pediátricos. Apresenta muitas vantagens: facilidade de execução, segurança, diminuição da necessidade de anestésicos inalatórios e analgésicos no período intra-operatório, analgesia pós-operatória cuja duração depende do anestésico local e do adjuvante usado (Armitage, 1985; 1986). 
A anestesia regional empregada em crianças e lactentes difere em muitos aspectos da que é realizada em adultos devido à anatomia e à farmacocinética e farmacodinâmica da criança. Outras diferenças estão relacionadas aos fatores comportamentais e ao desenvolvimento neuropsicomotor, que exercem limitação na maneira como a anestesia regional é realizada nessa população, pois o emprego de técnicas regionais na maioria das vezes está associado ao uso de sedação profunda ou anestesia geral. Outro fator importante na realização da anestesia regional em criança é a escolha do agente anestésico local, cuja duração deve ser prolongada o suficiente para garantir adequada analgesia no pós-operatório (Ivani e De Negri, 2001; Gunter, 2002). Esta escolha é particularmente importante, quando a anestesia regional é empregada em dose única para pacientes operados em regime ambulatorial.

\subsubsection{Considerações anatômicas}

Apesar do desafio que a realização de anestesia regional representa para o anestesiologista por causa do pequeno tamanho dos lactentes e crianças, e do temor de lesão de estruturas nervosas ou punção de dura-máter, a peridural sacra é uma técnica mais segura quando comparada com a peridural lombar.

O cone medular da medula espinhal e a dura-máter são localizados mais caudalmente na criança que nos adultos, o que assegura maior margem de segurança para a realização da punção na região sacral em relação à punção lombar. A partir de um ano de idade o cone medular termina no nível da primeira vértebra lombar e o saco dural encontra-se entre a primeira e segunda vértebras sacrais. (Krane, 1988; Dalens, 1990; Pullerits e Holzman, 1993; Cook et al., 1995).

O hiato sacral é superficial, suficientemente grande e fácil de localizar a palpação e a gordura localizada no espaço peridural é quase 
ausente e com aspecto gelatinoso nas crianças pequenas. Este último fator é o responsável pela difusão do anestésico local até a região torácica a partir da sua administração no espaço sacral. Assim, é possível promover analgesia para procedimentos abdominais altos e torácicos pela administração de anestésicos locais via sacral, empregando volumes de 1 a $1,25 \mathrm{~mL} / \mathrm{kg}$. Contudo, a massa de anestésico local empregado na solução a ser utilizada, deve respeitar a dose máxima permitida para cada agente (Dalens, 1990; Cook et al., 1995

A bainha fibrosa e a mielinização nos troncos nervosos está incompletamente desenvolvida até os 2 anos de idade, significando que concentrações baixas de anestésico local podem promover analgesia e relaxamento muscular adequado nessa faixa etária. Benzon et al. (1988), demonstraram que a lidocaína diminuiu a amplitude do potencial de ação e a velocidade de condução do impulso nas fibras mielinizadas do tipo $A$ de coelhos lactentes e adultos comparados com os animais da faixa etária intermediária. Neste estudo, as fibras C não mielinizadas, não apresentaram aumento da sensibilidade ao bloqueio de condução com altas concentrações de lidocaína. Estes resultados confirmam, que em crianças não é necessária à utilização de alta concentração de anestésicos locais para produzir analgesia, portanto a bupivacaína não deve ser usada em concentração maior que $0,25 \%$ nessa população (Nishina et al., 1999).

\subsubsection{Considerações farmacocinéticas e farmacodinâmicas}

Aspecto importante da farmacocinética em crianças é a concentração plasmática diminuída de albumina e $\alpha_{1}$ glicoproteína ácida, esta ultima a principal proteína à qual os anestésicos locais se ligam (Hannallah et al., 1987; Mikawa et al., 1993; Rice, 1996; Motsch et al., 1997; Mazoit e Dalens, 2004). 
A bupivacaína SR50 é um anestésico local muito utilizado em anestesia pediátrica por suas propriedades físico-químicas que permitem obter bloqueio motor e sensitivo de longa duração (Dalens, 1989).

A levobupivacaína apresenta menor toxicidade sistêmica e menor intensidade de bloqueio motor, sendo indicada para a anestesia pediátrica, uma vez que o bloqueio motor intenso no pós-operatório, é interpretado pela criança como sensação tão desagradável como a dor (Armitage, 1985).

\subsection{Hipótese}

Uma vez que a bupivacaína S75R25, com $75 \%$ da forma levógira (S-) e $25 \%$ da forma dextrógira ( $R+$ ), apresenta menor toxicidade sistêmica e induz menos bloqueio motor que a SR50, é possível supor que a bupivacaína S75R25 seja mais adequada do que a SR50 para a anestesia regional em crianças.

É possível supor que a bupivacaína S75R25 seja mais adequada do que a SR50 para a anestesia regional em crianças, pois apresenta menor toxicidade sistêmica, induz bloqueio motor de menor intensidade e bloqueio sensitivo de longa duração, 


\section{OBJETIVOS}


Comparar a intensidade e a duração do bloqueio motor, a duração da analgesia, o consumo de sevoflurano $e$ as alterações hemodinâmicas em crianças, que receberam anestesia peridural sacra com a bupivacaína racêmica (bupivacaína SR50) ou com a mistura de $75 \%$ de S-bupivacaína com 25\% R-bupivacaína (bupivacaína S75R25) associados ou não com a clonidina, para serem submetidas a cirurgias infra-umbilicais de pequeno porte. 


\section{MÉTODOS}




\subsection{Aspectos éticos}

Este estudo foi conduzido em crianças do Instituto Pedro de Alcântara - Instituto da Criança do Hospital das Clínicas da Faculdade de Medicina da Universidade de São Paulo, após a aprovação do projeto de pesquisa pelo Comitê de Ética para Análise de Projetos de Pesquisa.

O consentimento pós-informado, cuja redação obedeceu às recomendações da Resolução $n^{\circ}$ 196, de 10 de outubro de 1996, do Conselho Nacional de Saúde (Anexo 1), foi apresentado e devidamente explicado ao responsável legal pela criança durante a consulta realizada em regime ambulatorial. Nessa ocasião, o responsável, após ser esclarecido sobre a pesquisa, assinou o termo de consentimento pós-informado para que o menor pudesse participar do estudo.

Este estudo se caracterizou por ser uma investigação clínica, prospectiva, controlada, aleatória, duplamente encoberta, abrangendo a população pediátrica submetida a cirurgias de pequeno porte, infraumbilicais, com agendamento prévio. A coleta de dados iniciou em maio de 2002 e terminou em julho de 2004.

\subsection{Critérios de inclusão e exclusão}

Foram critérios para a inclusão no protocolo: crianças de ambos sexos, entre 5 e 10 anos de idade, com risco anestésico I ou II de acordo com os critérios adotados pela Sociedade Americana de Anestesiologia (ASA), a serem submetidas a cirurgias eletivas infra-umbilicais de pequeno porte.

Foram critérios para exclusão no protocolo: crianças portadoras de cardiopatia, ou em uso de antidepressivo para tratamento de enurese noturna, ou em uso de clonidina para teste de estimulação do hormônio de 
crescimento, alergia a clonidina ou a anestésicos locais, bem como o não consentimento do responsável, sem que isso pudesse interferir no tratamento ou causar prejuízo para o tratamento do paciente.

\subsection{Grupos de estudo}

Após a obtenção da assinatura do responsável legal no termo de consentimento pós-informado, 40 crianças foram aleatoriamente distribuídas em 4 grupos, cada um com 10 pacientes, de acordo com o tipo de solução utilizada:

\section{Grupo S75R25+SF; \\ Grupo SR50+SF; \\ Grupo S75R25+Clonidina; \\ Grupo SR50+Clonidina.}

A dose $1,75 \mathrm{mg} / \mathrm{kg}$ de anestésico local foi aplicada aos pacientes de todos os grupos. A dose $20 \mu \mathrm{g} / \mathrm{kg}$ de clonidina foi aplicada aos pacientes dos grupos S75R25+Clonidina e SR50+Clonidina. A dose máxima de clonidina foi de $140 \mu \mathrm{g}$.

O estudo foi duplamente encoberto. Os fármacos foram preparados no dia do estudo pelo farmacêutico da Instituição e colocados em 4 frascos identificados por números de 1 a 4 . Os frascos 1 e 2 continham anestésico local em concentração de $0,25 \%$ e os frascos 3 e 4 continham solução de cloreto de sódio a $0,9 \%$ ou clonidina na concentração de $20 \mu \mathrm{g} / \mathrm{mL}$ diluída em solução de cloreto de sódio a $0,9 \%$; de maneira que em cada paciente foi usado o conteúdo do frasco 1 ou 2 associado ao do frasco 3 ou 4. Aos frascos de anestésico local foi adicionado $1 \mathrm{~mL}$ de solução contendo $50 \mu \mathrm{g}$ de adrenalina, após a retirada de volume igual ao que foi acrescentado, resultando na concentração de adrenalina igual a 1:400.000. 
Em todos os grupos o volume usado foi de $0,7 \mathrm{~mL} / \mathrm{kg}$, correspondendo à dose de $1,75 \mathrm{mg} / \mathrm{kg}$ de anestésico local. Para manter a uniformidade de volume em todas as crianças estudadas, antes da adição de $1 \mathrm{~mL} / 10 \mathrm{~kg}$ ou $2 \mu \mathrm{g} / \mathrm{kg}$ de adjuvante, volume semelhante àquele que seria acrescentado foi retirado do volume total de anestésico local calculado para cada criança. O volume máximo da solução utilizada no espaço peridural sacral foi de $20 \mathrm{~mL}$.

\subsection{Coleta dos dados}

Todas as crianças receberam por via oral midazolam $0,5 \mathrm{mg} / \mathrm{kg}$ como medicação pré-anestésica, trinta minutos antes do inicio da anestesia. No momento da admissão ao centro cirúrgico, a sedação foi avaliada por uma escala contendo 4 escores. (Anexo 2). A mesma escala foi utilizada para avaliação da sedação no período pós-operatório.

Antes do início da indução anestésica foram monitorizadas as seguintes variáveis: freqüência cardíaca $(F C)$, traçado eletrocardiográfico (ECG) em derivação II com o monitor Hewlett Packard ${ }^{\circledR}$ model 78833B ou Hewlett Packard ${ }^{\circledR}$ M 1176 A-model 66, pressão arterial não invasiva sistólica (PAS), diastólica (PAD), e média (PAM) com o monitor Hewlett Packard ${ }^{\circledR} M$ 1176 A - model 66 ou Dixtal ${ }^{\circledR}$ DX 2710, saturação periférica de oxigênio $\left(\mathrm{SpO}_{2}\right)$ com o monitor Ohmeda Biox 3700-BOC Health Care ${ }^{\circledR}$ ou Hewlett Packard $^{\circledR}$ M1176A - model 66.

Os registros das medidas da FC, da PAS, da PAD, da PAM e da $\mathrm{SpO}_{2}$ foram realizados antes da indução anestésica (IN), durante a indução (IND), antes da introdução do tubo orotraqueal (IOT), após a IOT e a cada cinco minutos até o final do procedimento. 
Para hidratação e reposição de perdas no período operatório foi utilizada solução de Ringer com lactato com velocidade de infusão de 6 a 8 $\mathrm{mL} / \mathrm{kg} / \mathrm{h}$, e nenhuma criança necessitou de correção da glicemia.

A indução anestésica foi realizada com sevoflurano, oxigênio e óxido nitroso a $50 \%$, sendo mantido o fluxo total de $4 \mathrm{~L} / \mathrm{min}$. Após a indução anestésica com máscara facial, foi puncionada veia no membro superior e injeção de propofol na dose de $2 \mathrm{mg} / \mathrm{kg}$, para facilitar a IOT. Após a IOT foi monitorizado o dióxido de carbono expirado $\left(\mathrm{EtCO}_{2}\right)$ com o monitor Ohmeda BIOX $5200 \mathrm{CO}_{2}$ Monitor, BOC Health Care ${ }^{\circledR}$. Para indução anestésica a ventilação manual assistida foi realizada com sistema Mapleson $D$, e a manutenção da anestesia com o sistema Mapleson A em respiração espontânea.

Após a IOT a criança era colocada em decúbito lateral esquerdo sendo realizada a anti-sepsia local, com material descartável apropriado. A punção no hiato sacro foi realizada com agulha com mandril diâmetro $22 \mathrm{G} x$ 2" / 0,73 x 50mmm modelo Perican Paed ${ }^{\circledR}$ - Laboratórios B Braun ${ }^{\circledR}$ do Brasil $\mathrm{SA}$.

Valores de PAS e/ou FC iguais ou maiores que $30 \%$ dos valores basais medidos antes da indução foram tomados como indicativo para aumentar a concentração de sevoflurano. Se o aumento da concentração de sevoflurano não era suficiente para a PAS e FC retornarem aos valores basais, era utilizado fentanil por via venosa em dose de $1 \mu \mathrm{g} / \mathrm{kg}$. Valores de PAS e/ou FC menores que $30 \%$ dos valores basais foram indicativos para diminuir a concentração de sevoflurano e proceder à administração venosa de vasopressor e atropina, respectivamente, se os valores não se normalizassem.

O bloqueio motor foi avaliado de acordo com a escala de Bromage (Anexo 4) (Bromage, 1969) após o despertar da anestesia geral e 
simultaneamente a cada avaliação horária durante as primeiras $8 \mathrm{~h}$ após o término do procedimento cirúrgico.

Foi considerado como duração do bloqueio sensitivo o tempo entre a administração das soluções no espaço peridural sacral e o primeiro resgate de analgesia solicitado pela criança ou avaliado como necessário pela escala de avaliação da dor. A analgesia pós-operatória foi avaliada pela escala objetiva para avaliar a dor (OPS) descrita por Hannallah et al. (1987). A analgesia pós-operatória foi avaliada na primeira hora após o término da operação e a cada $2 \mathrm{~h}$, durante as primeiras $8 \mathrm{~h}$ do pós-operatório isto é, nos momentos: 1, 2, 4, 6 e 8h, com registro simultâneo dos sinais vitais. A medicação resgate foi administrada sempre que o índice pela escala OPS era igual ou superior a 6 . Foram registrados o horário, a dose e o analgésico utilizado, bem como o número de vezes que foi necessária a sua administração. Após $24 \mathrm{~h}$ do procedimento, o responsável pela criança forneceu ao pesquisador, informação por telefone, sobre queixa de dor, uso de analgésico explicitando a dose e o horário de administração.

O vaporizador empregado para a vaporização do sevoflurano foi o vaporizador com fluxo regulável para câmara de vaporização (SIVA modelo 1415 Takaoka $^{\circledR}$ com sistemas Pinomatic ${ }^{\circledR}$, Dilumatic $^{\circledR}$ e mini Pinomatic $^{\circledR}$ - $20^{\circ} \mathrm{C} / 101 \mathrm{Kpa}$ ) ou o calibrado para concentrações prédeterminadas (Sevovapor ${ }^{\circledR}$ modelo 1225 Takaoka $^{\circledR}$ ). Durante o estudo foi avaliado o consumo de sevoflurano tomando a concentração utilizada durante o procedimento como uma medida indireta de avaliação. Quando necessário foi utilizada fórmula descrita em anexo para esse cálculo (Anexo 3). O registro da concentração de sevoflurano ou do fluxo de vaporização da câmara foi feito a cada 5 minutos, durante todo procedimento.

O tempo de despertar da anestesia foi considerado o tempo decorrido entre a retirada do tubo endotraqueal e a abertura dos olhos espontânea ou após estímulo verbal. Em todas as crianças a retirada do 
tubo endotraqueal foi feita em plano anestésico para não falsear a avaliação da sedação no período pós-operatório.

\subsection{Análise estatística}

Foram realizadas as comparações entre os grupos para a avaliar a intensidade e duração do bloqueio motor, da duração da analgesia pósoperatória, o consumo de sevoflurano, a PAS e a FC no pós-operatório.

Para as variáveis com resposta categorizada e avaliada em um único momento, os grupos foram comparados pela aplicação do teste exato de Fisher (Rosner, 1986a). Para variáveis contínuas os grupos foram comparados pela Análise de Variância (ANOVA) (Rosner, 1986b), ou pelo teste de Kruskal-Wallis (Rosner, 1986c).

A comparação dos grupos, quanto às variáveis estudadas em mais de um momento, foi feita pela ANOVA para medidas repetidas. (Timm, 1975). A suposição de distribuição normal dos dados foi verificada utilizandose o gráfico de probabilidade normal e os testes de Shapiro-Wilk e de Kolmogorov-Smirnov com o objetivo de validar os resultados da comparação dos grupos pela ANOVA para medidas repetidas. (Neter et al., 1990).

Para as variáveis que não satisfizeram a suposição de normalidade, foram procuradas transformações matemáticas que as normalizassem. Como não foi encontrada nenhuma transformação adequada, a ANOVA para medidas repetidas foi utilizada, com a condição de uma interpretação cautelosa dos resultados. O teste de Kruskal-Wallis foi aplicado para as variáveis sem distribuição normal em cada momento de avaliação, com o objetivo de comparar os grupos. As variáveis que não satisfizeram a suposição de normalidade foram os valores da escala OPS avaliada no período de $8 \mathrm{~h}$ de observação no pós-operatório, a $\mathrm{SpO}_{2}$ 
avaliada no início e indução da anestesia, antes e após a IOT, e o bloqueio motor.

O nível de significância igual a $5 \%$ foi adotado em todas as análises estatísticas realizadas nesse estudo, sendo o nível descritivo de $p$ menor ou igual a 0,05 foi considerado significante. 
4. RESULTADOS 


\subsection{Idade e peso}

A idade e o peso apresentaram distribuição uniforme em todos os grupos, não houve diferença significativa entre eles quando comparados entre si, e estão dispostos na tabela 1.

Tabela 1 - Distribuição das crianças estudadas de acordo com a idade e o peso.

\begin{tabular}{|c|c|c|c|c|c|c|c|c|}
\hline Variável & $\begin{array}{lllllll}G & \mathbf{r} & \mathbf{u} & \mathbf{p} & \mathbf{0} & \mathbf{s}\end{array}$ & $\mathbf{n}$ & mínimo & máximo & mediana & média & D P & $\mathrm{p}$ \\
\hline \multirow{4}{*}{$\begin{array}{l}\text { Id a d e } \\
(\text { anos })\end{array}$} & S75R25+Clonidina & 10 & 5,00 & 10,00 & 8,00 & 7,80 & 1,87 & \multirow[t]{4}{*}{0,2366} \\
\hline & $S 75 R 25+S F$ & 10 & 5,00 & 10,00 & 6,50 & 7,10 & 1,85 & \\
\hline & SR50+Clonidina & 10 & 5,00 & 10,00 & 6,50 & 6,80 & 1,87 & \\
\hline & $S R 50+S F$ & 10 & 5,00 & 8,00 & 6,00 & 6,20 & 1,23 & \\
\hline \multirow{4}{*}{$\begin{array}{l}P \text { e s o } \\
\left(\begin{array}{ll}k & g\end{array}\right)\end{array}$} & S75R25+Clonidina & 10 & 17,70 & 36,00 & 26,85 & 26,64 & 5,83 & \multirow[t]{4}{*}{0,1301} \\
\hline & S $75 R 25+S F$ & 10 & 17,50 & 26,90 & 20,38 & 21,80 & 3,64 & \\
\hline & SR50+Clonidina & 10 & 17,10 & 32,20 & 23,10 & 23,41 & 5,27 & \\
\hline & $S R 50+S F$ & 10 & 17,30 & 30,90 & 22,00 & 22,47 & 4,09 & \\
\hline
\end{tabular}




\subsection{Sexo}

Como pode ser observado na tabela 2 houve predominância do sexo masculino, pois a maior parte das operações foi relacionada ao aparelho genital masculino, como pode ser verificado pela tabela 3.

Tabela 2 - Distribuição das crianças estudadas de acordo com o sexo.

\begin{tabular}{ccccccccccc}
\hline & & $\begin{array}{c}\text { S75R25+ } \\
\text { Clonidina }\end{array}$ & $\begin{array}{c}\text { S75R25+ } \\
\text { S F }\end{array}$ & \multicolumn{2}{c}{$\begin{array}{c}\text { S R 5 0 + } \\
\text { Clonidina }\end{array}$} & $\begin{array}{c}\text { SR50+ } \\
\text { S F }\end{array}$ & p \\
\hline Variável & Categoria & $\mathrm{n}$ & $\%$ & $\mathrm{n}$ & $\%$ & $\mathrm{n}$ & $\%$ & $\mathrm{n}$ & $\%$ & (Fisher) \\
\hline & $\mathbf{F}$ & 2 & 20,0 & 3 & 30,0 & 4 & 40,0 & 2 & 20,0 & 0,8655 \\
S e x 0 & & & & & & & & & & \\
& $\mathbf{M}$ & 8 & 80,0 & 7 & 70,0 & 6 & 60,0 & 8 & 80,0 & \\
\hline
\end{tabular}

Tabela 3 - Distribuição das crianças estudadas de acordo com o tipo de operação.

\begin{tabular}{|c|c|c|c|c|}
\hline$P r o c e d i m e n t o s$ & S75R25+Clonidina & S75R25+SF & SR50+Clonidina & SR50+SF \\
\hline Hipospádia & 2 & 0 & 3 & 2 \\
\hline Orquipexia & 4 & 0 & 2 & 0 \\
\hline Hérnia inguinal & 3 & 8 & 5 & 0 \\
\hline Hérnia inguinal + postoplastia & 0 & 1 & 0 & 5 \\
\hline Hérnia inguinal + postectomia & 0 & 0 & 0 & 3 \\
\hline Postectomia + prótese & 1 & 0 & 0 & 0 \\
\hline
\end{tabular}




\begin{tabular}{lcccc} 
Postectomia + biópsia testículo & 0 & 1 & 0 & 0 \\
\hline Total & 10 & 10 & 10 & 10 \\
\hline
\end{tabular}




\subsection{Duração das operações}

A duração das operações variou bastante entre os grupos sendo maior no grupo SR50+Clonidina. Os procedimentos deste grupo tiveram duração de aproximadamente $50 \%$ maior do que os do grupo S75R25+SF, como pode ser observado na tabela 4.

Tabela 4 - Duração das operações nos grupos estudados.

\begin{tabular}{llllllll}
\hline G r u p o s & n & Mínimo & Máximo & Mediana & Média & D P & p \\
\hline S75R25+Clonidina & 10 & 54,00 & 130,00 & 91,00 & 91,70 & 26,83 & 0,0908 \\
S 7 5 R 2 5 + S F & 10 & 43,00 & 107,00 & 63,50 & 66,60 & 19,82 & \\
SR50+Clonidina & 10 & 46,00 & 154,00 & 94,00 & 95,70 & 38,08 & \\
S R 5 0 + S F & 10 & 69,00 & 130,00 & 81,50 & 87,10 & 17,67 & \\
\hline
\end{tabular}




\section{operação \\ 4.4. Intervalo entre a realização do bloqueio e o início da}

O intervalo de tempo entre a punção para a realização da anestesia caudal e o inicio da operação variou pouco entre os grupos, sendo maior no grupo S75R25+Clonidina e menor no grupo S75R25+SF. Esse intervalo diferente entre os grupos provavelmente foi devido a características próprias das operações realizadas e das equipes envolvidas nas operações, não guardando correlação com o tempo de latência do anestésico local, uma vez que os pacientes estiveram sob anestesia geral durante todo o ato operatório.

Tabela 5 - Tempo, em minutos, entre a realização do bloqueio e o inicio da operação.

\begin{tabular}{lllllllll}
\hline G r u p o s & n & Mínimo & Máximo & Mediana & Média & DP & p \\
\hline S75R25 +Clonidina & 10 & 5,00 & 36,00 & 12,50 & 14,80 & 8,56 & 0,3149 \\
S75R 25 + S F & 10 & 5,00 & 25,00 & 8,00 & 10,30 & 6,15 & \\
SR50 +Clonidina & 10 & 7,00 & 19,00 & 11,50 & 12,10 & 4,18 & \\
S R 5 0 + S F & 10 & 3,00 & 22,00 & 12,00 & 12,10 & 5,45 & \\
\hline
\end{tabular}




\subsection{Intensidade do bloqueio motor}

O bloqueio motor da $1^{\mathrm{a}}$ até a $4^{\mathrm{a}}$.h de avaliação foi mais intenso no grupo SR50+Clonidina, seguido pelo grupo S75R25+Clonidina, que foi maior que o grupo SR50+SF e o menor valor foi do grupo S75R25+SF. Na $6^{\text {ah }}$ o bloqueio motor estava presente apenas nos grupos S75R25+Clonidina e SR50+Clonidina sendo mais intenso no grupo S75R25+Clonidina. Na $8^{\text {ah }}$ nenhum dos grupos apresentava bloqueio motor. Quando os momentos de avaliação ( $1^{\mathrm{a}}$ e $\left.4^{\mathrm{a} h}\right)$ foram comparados no mesmo grupo houve diferença significativa nos grupos S75R25+SF, SR50+Clonidina e SR50+SF, de acordo com a ANOVA para medidas repetidas. Nesses grupos o bloqueio motor foi mais acentuado na $1^{\text {ah }}$ em relação a $4^{\text {ah }}$. Os dados podem ser analisados na tabela 6 e na figura 1.

Tabela 6 - Intensidade do bloqueio motor.

\begin{tabular}{|c|c|c|c|c|c|c|c|}
\hline Momento & $G \quad r \quad p \quad o$ & $\frac{B \quad I}{n}$ & $\frac{0 \mathrm{q} \mathrm{u}}{\text { mínimo }}$ & $\frac{e \text { i } 0}{\text { máximo }}$ & $\frac{1 \circ \mathrm{t} \quad \mathrm{o}}{\text { mediana }}$ & média & DP \\
\hline & S75R25+Clonidina & 8 & 0,00 & 3,00 & 0,50 & 0,88 & 1,13 \\
\hline \multirow[t]{4}{*}{$1^{a}$ hora } & $S 75 R 25+S F$ & 10 & 0,00 & 2,00 & 0,50 & 0,70 & 0,82 \\
\hline & SR50+Clonidina & 9 & 1,00 & 3,00 & 2,00 & 1,89 & 0,60 \\
\hline & $S R 50+S F$ & 7 & 0,00 & 2,00 & 0,00 & 0,86 & 1,07 \\
\hline & S75R25+Clonidina & 10 & 0,00 & 3,00 & 0,00 & 0,70 & 1,16 \\
\hline \multirow[t]{4}{*}{$2^{a}$ hora } & $S 75 R 25+S F$ & 10 & 0,00 & 2,00 & 0,00 & 0,40 & 0,70 \\
\hline & SR50+Clonidina & 10 & 0,00 & 2,00 & 1,00 & 1,10 & 0,74 \\
\hline & $S R 50+S F$ & 10 & 0,00 & 2,00 & 0,00 & 0,50 & 0,71 \\
\hline & S75R25+Clonidina & 10 & 0,00 & 3,00 & 0,00 & 0,40 & 0,97 \\
\hline \multirow[t]{4}{*}{$4^{a}$ hora } & $S 75 R 25+S F$ & 10 & 0,00 & 1,00 & 0,00 & 0,20 & 0,42 \\
\hline & SR50+Clonidina & 10 & 0,00 & 2,00 & 0,00 & 0,70 & 0,95 \\
\hline & $S R 50+S F$ & 10 & 0,00 & 1,00 & 0,00 & 0,20 & 0,42 \\
\hline & S75R25+Clonidina & 10 & 0,00 & 3,00 & 0,00 & 0,30 & 0,95 \\
\hline \multirow[t]{4}{*}{$6^{a}$ hora } & $S 75 R 25+S F$ & 10 & 0,00 & 0,00 & 0,00 & 0,00 & 0,00 \\
\hline & SR50+Clonidina & 10 & 0,00 & 1,00 & 0,00 & 0,10 & 0,32 \\
\hline & $S R 50+S F$ & 10 & 0,00 & 0,00 & 0,00 & 0,00 & 0,00 \\
\hline & S75R25+Clonidina & 10 & 0,00 & 0,00 & 0,00 & 0,00 & 0,00 \\
\hline \multirow[t]{3}{*}{$8^{a}$ hora } & $S 75 R 25+S F$ & 10 & 0,00 & 0,00 & 0,00 & 0,00 & 0,00 \\
\hline & SR50+Clonidina & 10 & 0,00 & 0,00 & 0,00 & 0,00 & 0,00 \\
\hline & $S R 50+S F$ & 10 & 0,00 & 0,00 & 0,00 & 0,00 & 0,00 \\
\hline
\end{tabular}


$\mathrm{Na}$ tabela 6 o número de pacientes é diferente em cada grupo porque na $1^{\text {ah }} 2$ crianças no grupo S75R25+Clonidina, 1 no grupo SR50+Clonidina, e 3 no grupo SR50+SF não puderam ser avaliadas, pois estavam sedadas e não respondiam a estímulos verbais.

Figura 1 - Intensidade do bloqueio motor.

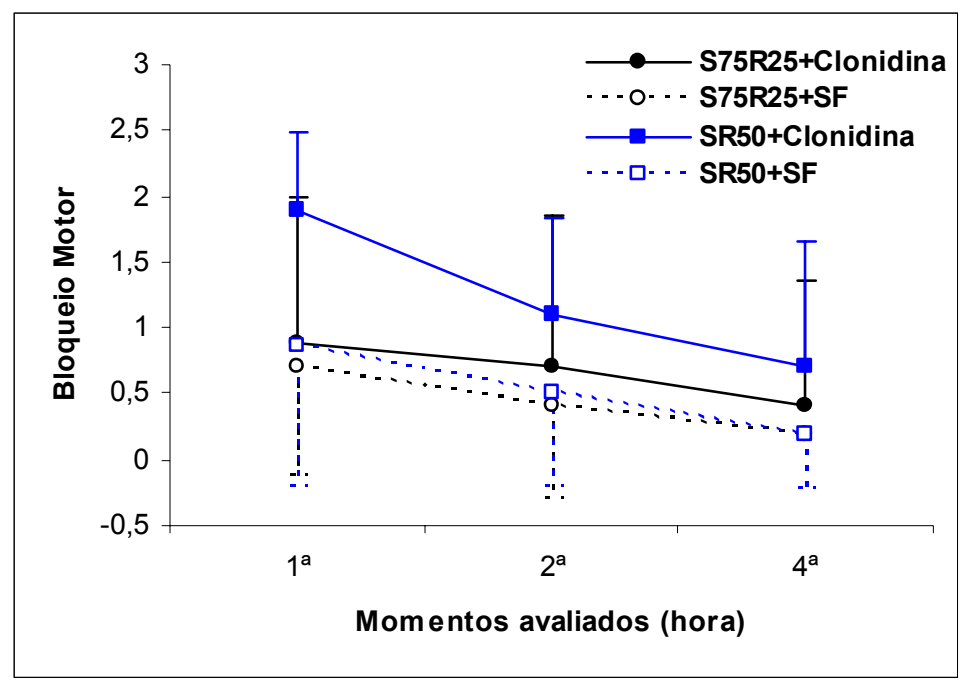

Como pode ser verificado nas tabelas 7 e 8 , houve diferença significante na $1^{\text {a }} \mathrm{h}$ no grupo SR50+Clonidina, e quando se comparou a $1^{\mathrm{a}}$ com a $4^{\mathrm{a}} \mathrm{h}$ nos grupos S75R25+SF, SR50+Clonidina e SR50+SF. avaliação.

Tabela 7 - Comparação do bloqueio motor nos momentos de

\begin{tabular}{cc}
\hline Momento da Avaliação & $\mathbf{p}$ \\
\hline $1^{\mathrm{a}}$ hora & $0,0408^{*}$ \\
$2^{\mathrm{a}}$ hora & 0,1678 \\
$4^{\mathrm{a}}$ hora & 0,5368 \\
\hline
\end{tabular}

${ }^{*}$ significativo para $p \leq 0,05$

A análise estatística pelo método de Kruskal-Wallis permitiu verificar que apenas o grupo SR50+Clonidina foi estatisticamente diferente dos demais na $1^{\mathrm{a}} \mathrm{h}$. 
Tabela 8 - Comparação entre a intensidade do bloqueio motor entre os grupos e os momentos estudados.

\begin{tabular}{lc}
\hline Momento das comparações & $\mathbf{p}$ \\
\hline $\mathrm{G} 1=\mathrm{G} 2=\mathrm{G} 3=\mathrm{G} 4(\mathrm{~T} 1)$ & $0,0003^{*}$ \\
$\mathrm{G} 1=\mathrm{G} 3(\mathrm{~T} 1)$ & $0,0130^{*}$ \\
$\mathrm{G} 2=\mathrm{G} 4(\mathrm{~T} 1)$ & 0,8677 \\
$\mathrm{G} 1=\mathrm{G} 2(\mathrm{~T} 1)$ & 0,6259 \\
$\mathrm{G} 3=\mathrm{G} 4(\mathrm{~T} 1)$ & $0,0028^{*}$ \\
$\mathrm{G} 1=\mathrm{G} 2=\mathrm{G} 3=\mathrm{G} 4(\mathrm{~T} 2)$ & 0,1409 \\
$\mathrm{G} 1=\mathrm{G} 2=\mathrm{G} 3=\mathrm{G} 4(\mathrm{~T} 3)$ & 0,4293 \\
$\mathrm{~T} 1=\mathrm{T} 3(\mathrm{G} 1)$ & 0,1581 \\
T1 $=\mathrm{T} 3(\mathrm{G} 2)$ & $0,0253^{*}$ \\
$\mathrm{~T} 1=\mathrm{T} 3(\mathrm{G} 3)$ & $<.0001^{*}$ \\
T1=T3 (G4) & $0,0292^{*}$ \\
\hline${ }^{*}$ significativo para $\mathrm{p} \leq 0,05$ &
\end{tabular}

G1: grupo S75R25+Clonidina; G2: grupo S75R25+SF G3: grupo SR50+Clonidina; G4: grupo SR50+SF; T1: $1^{\text {a }}$ hora; T2: $2^{\mathrm{a}}$ hora; T3: $4^{\mathrm{a}}$ hora. 


\subsection{Analgesia pós-operatória}

A analgesia pós-operatória foi avaliada durante as primeiras 8 horas do pós-operatório, sendo utilizada a escala OPS. O grupo S75R25+SF exibiu os menores valores em todos os momentos avaliados até a $4^{\mathrm{a}} \mathrm{h}$, de acordo com a escala adotada. O grupo SR50+SF exibiu os valores mais altos em todos os momentos avaliados com exceção do momento 6 horas, no qual o grupo S75R25+SF apresentou valores maiores, como pode ser observado na tabela 9 e na figura 2. Esses valores não foram significantes quando submetidos a análise estatística.

Tabela 9 - Analgesia no pós-operatório, avaliada pela escala objetiva de avaliação da dor.

\begin{tabular}{|c|c|c|c|c|c|c|c|c|c|}
\hline \multirow[b]{2}{*}{ Momento } & \multirow[b]{2}{*}{ Grupo } & \multicolumn{8}{|c|}{ Valores } \\
\hline & & $\bar{n}$ & Mínimo & Máximo & Mediana & Média & $\mathrm{DP}$ & $\begin{array}{c}\text { ANOVA } \\
\text { (p) }\end{array}$ & $\begin{array}{c}\text { Kruskal } \\
\text { Wallis } \\
\text { (p) }\end{array}$ \\
\hline \multirow{4}{*}{$1^{\mathrm{a}}$ hora } & S75+R25+Clonidina & 10 & 0,00 & 2,00 & 0,00 & 0,20 & 0,63 & 0,2576 & 0,2960 \\
\hline & $\mathrm{S} 75 \mathrm{R} 25+\mathrm{SF}$ & 10 & 0,00 & 1,00 & 0,00 & 0,20 & 0,42 & & \\
\hline & SR50+Clonidina & 10 & 0,00 & 3,00 & 0,00 & 0,60 & 0,97 & & \\
\hline & SR50+SF & 10 & 0,00 & 8,00 & 0,00 & 1,60 & 2,67 & & \\
\hline \multirow{4}{*}{$2^{\mathrm{a}}$ hora } & S75R25+Clonidina & 10 & 0,00 & 4,00 & 0,00 & 0,80 & 1,32 & 0,4071 & 0,2981 \\
\hline & S75R25+SF & 10 & 0,00 & 4,00 & 0,00 & 0,40 & 1,26 & & \\
\hline & SR50+Clonidina & 10 & 0,00 & 2,00 & 0,00 & 0,40 & 0,70 & & \\
\hline & SR50+SF & 10 & 0,00 & 4,00 & 0,50 & 1,30 & 1,70 & & \\
\hline \multirow{4}{*}{$4^{\mathrm{a}}$ hora } & S75R25+Clonidina & 10 & 0,00 & 5,00 & 0,00 & 1,10 & 1,91 & 0,0854 & 0,2021 \\
\hline & $S 75 R 25+S F$ & 10 & 0,00 & 3,00 & 0,00 & 0,40 & 0,97 & & \\
\hline & SR50+Clonidina & 10 & 0,00 & 5,00 & 0,00 & 0,90 & 1,60 & & \\
\hline & SR50+SF & 10 & 0,00 & 5,00 & 3,00 & 2,10 & 1,91 & & \\
\hline \multirow{4}{*}{$6^{\mathrm{a}}$ hora } & S75R25+Clonidina & 10 & 0,00 & 5,00 & 0,00 & 1,00 & 1,63 & 0,2355 & 0,3212 \\
\hline & $S 75 R 25+S F$ & 10 & 0,00 & 6,00 & 3,50 & 2,70 & 2,45 & & \\
\hline & SR50+Clonidina & 10 & 0,00 & 3,00 & 0,50 & 1,00 & 1,15 & & \\
\hline & SR50+SF & 10 & 0,00 & 3,00 & 1,00 & 1,10 & 1,20 & & \\
\hline \multirow{4}{*}{$8^{\mathrm{a}}$ hora } & S75R25+Clonidina & 10 & 0,00 & 5,00 & 1,00 & 1,30 & 1,57 & 0,6719 & 0,6699 \\
\hline & S75R25+SF & 10 & 0,00 & 4,00 & 0,00 & 1,20 & 1,62 & & \\
\hline & SR50+Clonidina & 10 & 0,00 & 3,00 & 0,50 & 0,90 & 1,10 & & \\
\hline & SR50+SF & 10 & 0,00 & 3,00 & 1,50 & 1,50 & 1,08 & & \\
\hline
\end{tabular}


Os dados da avaliação estão expressos como média e desvio padrão dos valores. A comparação entre os grupos durante os mesmos momentos da observação, e entre os momentos no mesmo grupo não foi estatisticamente significante.

Figura 2 - Analgesia no pós-operatório avaliada pela escala objetiva para dor.

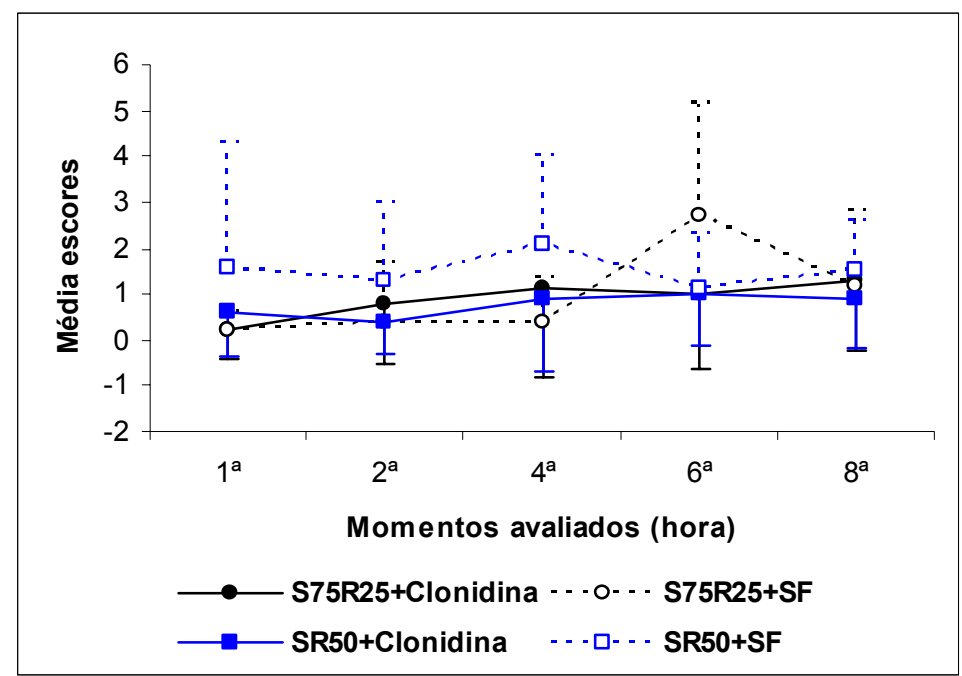

No eixo das abscissas estão representados os momentos de avaliação no pós-operatório, no eixo das ordenadas os valores obtidos nos grupos e expressos como média e desvio padrão. 


\subsection{Consumo de Sevoflurano}

Os valores do consumo de sevoflurano foram obtidos a partir da concentração utilizada durante o procedimento. Foram considerados dois momentos: até a IOT e após a IOT. Em todos os grupos estudados houve diminuição significativa da concentração de sevoflurano após IOT em relação ao momento considerado até a IOT. Quando os grupos foram comparados entre si após a IOT, não foi detectada significância estatística pelo teste de Kruskal-Wallis ou pela ANOVA para medidas repetidas, como pode ser visto nas tabelas 10 e 11 e na figura 3.

Tabela 10 - Consumo de sevoflurano até a intubação orotraqueal e após a intubação orotraqueal.

\begin{tabular}{clccc}
\hline Consumo Sevoflurano & \multicolumn{1}{c}{ Grupo } & n & Média & DP \\
\hline & S75R25+Clonidina & 10 & 4,81 & 1,27 \\
& S75R25+SF & 10 & 5,45 & 1,09 \\
Até IOT & SR50+Clonidina & 10 & 6,03 & 1,22 \\
& SR50+SF & 10 & 6,23 & 0,87 \\
\cline { 2 - 5 } & Total & 40 & 5,63 & 1,22 \\
\hline \multirow{3}{*}{ Após IOT } & S75R25+Clonidina & 10 & 2,83 & 0,98 \\
& S75R25+SF & 10 & 2,49 & 0,66 \\
& SR50+Clonidina & 10 & 2,73 & 1,12 \\
& SR50+SF & 10 & 2,42 & 0,98 \\
\cline { 2 - 5 } & Total & 40 & 2,61 & 0,93
\end{tabular}


Tabela 11 - Comparação do consumo de sevoflurano entre os grupos e os momentos estudados.

\begin{tabular}{lc}
\hline Momento das comparações & $\mathbf{p}$ \\
\hline $\mathrm{G} 1=\mathrm{G} 3(\mathrm{~T} 1)$ & $0,0284^{*}$ \\
$\mathrm{G} 2=\mathrm{G} 4(\mathrm{~T} 1)$ & 0,0747 \\
$\mathrm{G} 1=\mathrm{G} 2(\mathrm{~T} 1)$ & 0,2309 \\
$\mathrm{G} 3=\mathrm{G} 4(\mathrm{~T} 1)$ & 0,6666 \\
$\mathrm{G} 1=\mathrm{G} 2=\mathrm{G} 3=\mathrm{G} 4(\mathrm{~T} 2)$ & 0,7270 \\
$\mathrm{~T} 1=\mathrm{T} 2(\mathrm{G} 1)$ & $<.0001^{*}$ \\
$\mathrm{~T} 1=\mathrm{T} 2(\mathrm{G} 2)$ & $<.0001^{*}$ \\
$\mathrm{~T} 1=\mathrm{T} 2(\mathrm{G} 3)$ & $<.0001^{*}$ \\
$\mathrm{~T} 1=\mathrm{T} 2(\mathrm{G} 4)$ & $<.0001^{*}$ \\
\hline * significativo para $\mathrm{p} \leq 0,05$ &
\end{tabular}

G1: S75R25+Clonidina; G2: S75R25+SF; G3: SR50+Clonidina; G4: SR50+SF; T1: até a IOT; T2: após a IOT.

Figura 3 - Consumo de Sevoflurano, em concentração.

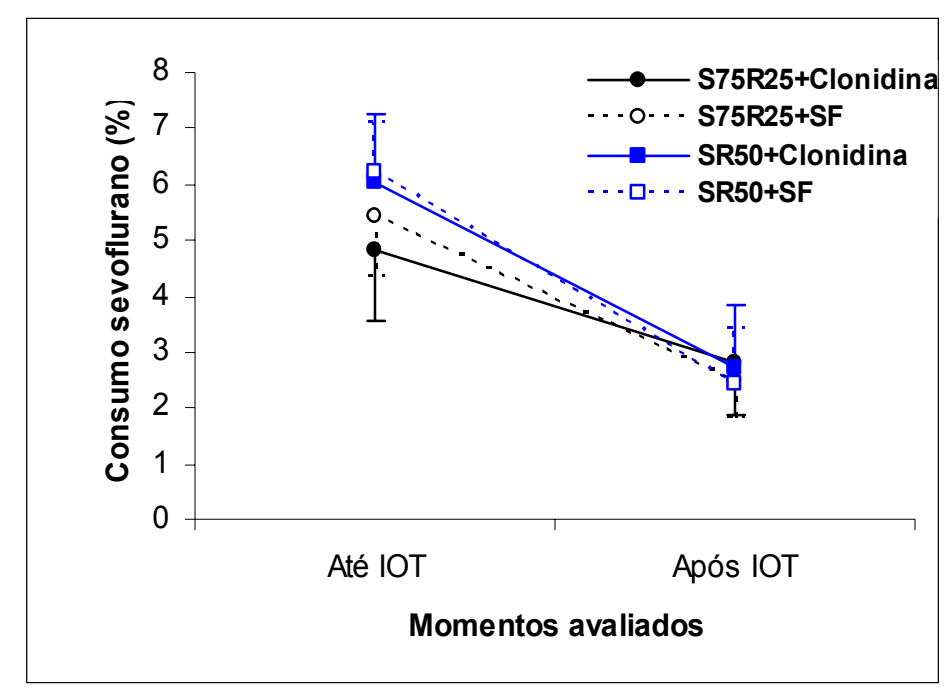

No eixo das abscissas estão representados os dois momentos de avaliação da concentração utilizada nos grupos estudados, no eixo das ordenadas os valores da concentração, expressos como média e desvio padrão. 


\subsection{Intervalo entre a punção sacral e a primeira dose de analgésico}

O intervalo entre a punção sacral e a primeira dose de analgésico foi obtida a partir dos dados da avaliação durante as primeiras 8 horas do pós-operatório e das informações fornecidas pelo responsável, por telefone, 24 horas após o procedimento. O maior intervalo foi para o grupo SR50+Clonidina e o menor para o grupo S75R25+SF, como pode ser visto na tabela 12 e na figura 4 , porém não houve diferença estatisticamente significante quando os valores de cada grupo foram comparados entre si.

Tabela 12 - Intervalo entre a punção sacral e a primeira dose de analgésico, em minutos.

\begin{tabular}{lcccccc}
\hline \multicolumn{1}{c}{ Grupo } & $\mathbf{n}$ & Mínimo & Máximo & Média & DP & p \\
\hline S75R25+Clonidina & 10 & 348,00 & 1425,00 & 728,00 & 481,57 & 0.7398 \\
S75R25+SF & 10 & 124,00 & 1427,00 & 715,50 & 505,90 & \\
SR50+Clonidina & 10 & 301,00 & 1427,00 & 901,80 & 440,55 & \\
SR50+SF & 10 & 127,00 & 1395,00 & 796,00 & 544,56 & \\
\hline
\end{tabular}


Figura 4 - Intervalo entre a punção sacral e a primeira dose de analgésico, em minutos.

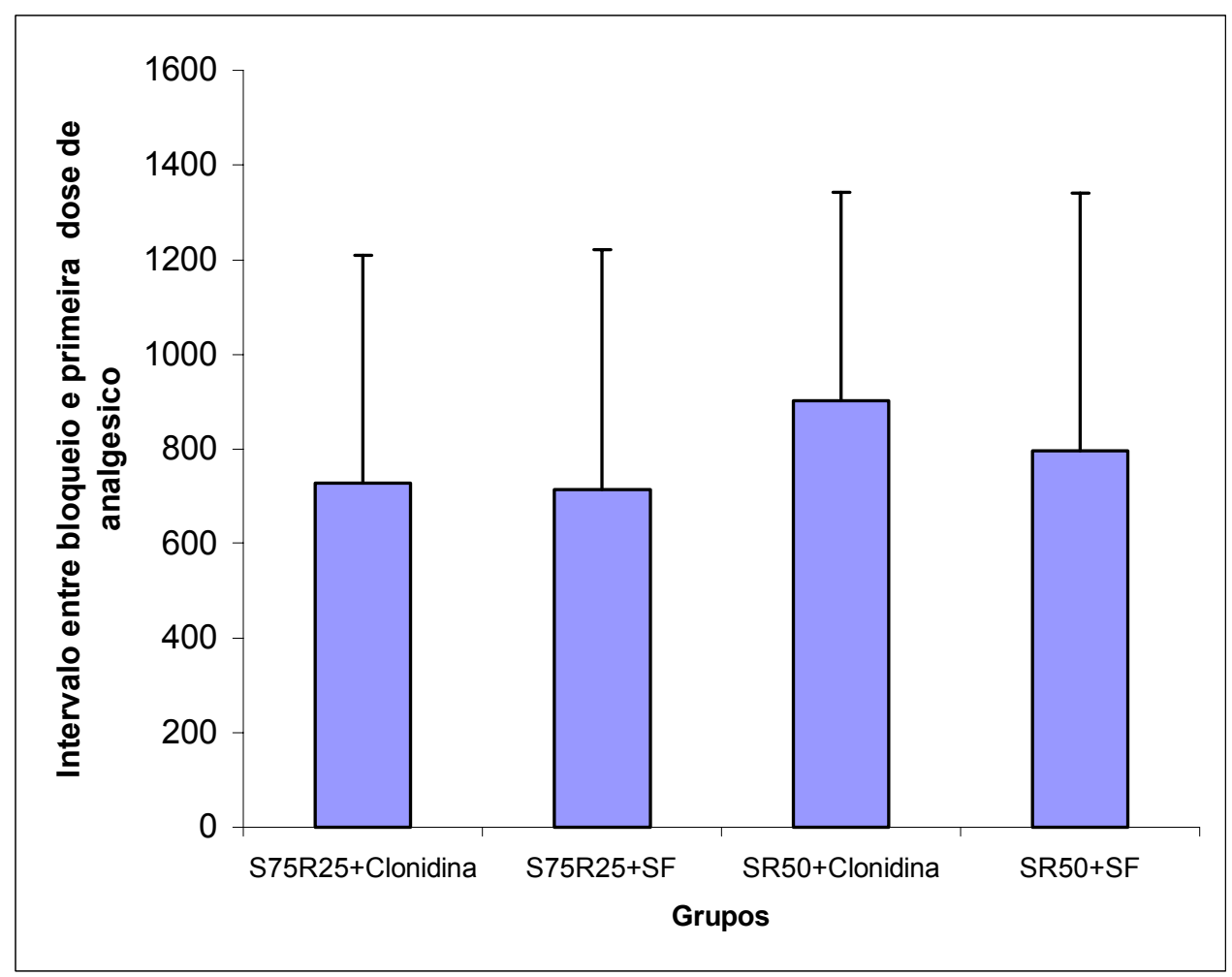

No grupo SR50+Clonidina a analgesia foi mais prolongada, porém não foi estatisticamente significante.

No eixo das abscissas são apresentados os grupos estudados e no eixo das ordenadas, os valores expressos em minutos, exibidos como média e desvio padrão. 


\subsection{Consumo de analgésicos na residência}

O consumo de analgésicos na residência foi avaliado pelo número de pacientes que necessitaram de analgésico e pelo número de vezes que o analgésico foi solicitado e aplicado pelo responsável. O grupo que mais necessitou de analgésico na residência foi o grupo S75R25+Clonidina e o que menos necessitou foi o grupo S75R25+SF. Não houve significância estatística quando os grupos foram comparados, como pode ser visto nas tabelas 13 e 14. residência.

Tabela 13 - Número de pacientes que usaram analgésico na

\begin{tabular}{cccccccccccc}
\hline Variável & \multicolumn{10}{c}{ Grupo } \\
\hline & \multicolumn{1}{c}{$\begin{array}{c}\text { S75R25+ } \\
\text { Clonidina }\end{array}$} & $\begin{array}{c}\text { S75R25+ } \\
\text { SF }\end{array}$ & $\begin{array}{c}\text { SR50+ } \\
\text { Clonidina }\end{array}$ & $\begin{array}{c}\text { SR50+ } \\
\text { SF }\end{array}$ & p \\
\cline { 2 - 11 } & Categoria & $\mathrm{n}$ & $\%$ & $\mathrm{n}$ & $\%$ & $\mathrm{n}$ & $\%$ & $\mathrm{n}$ & $\%$ & (Fisher) \\
\cline { 2 - 11 } $\begin{array}{c}\text { Número } \\
\text { de } \\
\text { pacientes }\end{array}$ & Não & 4 & 40,0 & 4 & 40,0 & 4 & 40,0 & 6 & 60,0 & 0,8354 \\
& Sim & 6 & 60,0 & 3 & 30,0 & 5 & 50,0 & 4 & 40,0 & \\
\hline
\end{tabular}

Dados apresentados como porcentagem da amostra, em cada grupo. residência.

Tabela 14 - Número de doses de analgésico usadas na

\begin{tabular}{clccccccc}
\hline Variável & \multicolumn{1}{c}{ Grupo } & $\mathbf{n}$ & Mínimo & Máximo & Mediana & Média & DP & p \\
\hline \multirow{3}{*}{$\begin{array}{c}\text { Número } \\
\text { de }\end{array}$} & S75R25 + Clonidina & 10 & 0,00 & 4,00 & 1,00 & 1,10 & 1,37 & 0,7990 \\
doses & S75R25 + SF & 7 & 0,00 & 2,00 & 0,00 & 0,57 & 0,79 & \\
& SR50 + Clonidina & 9 & 0,00 & 2,00 & 1,00 & 0,89 & 0,93 & \\
& SR50 + SF & 10 & 0,00 & 3,00 & 0,00 & 0,70 & 1,06 & \\
\hline
\end{tabular}




\subsection{Consumo de Fentanil durante a anestesia}

O consumo de fentanil durante a anestesia foi semelhante nos grupos quando submetidos ao teste exato de Fisher como pode ser visto pela tabela 15. Somente o grupo S75R25+SF não necessitou de opióide.

Tabela 15 - Consumo de fentanil durante a anestesia.

\begin{tabular}{ccccccccccc}
\hline \multicolumn{10}{c}{ Grupo } \\
\hline \multirow{2}{*}{ Variável } & Categoria & $\mathrm{n}$ & $\%$ & $\mathrm{n}$ & $\%$ & $\mathrm{n}$ & $\%$ & $\mathrm{n}$ & $\%$ & \\
\hline \multirow{2}{*}{ Clonidina } & $\begin{array}{c}\text { S75R25+ } \\
\text { SF }\end{array}$ & $\begin{array}{c}\text { SR50+ } \\
\text { Clonidina }\end{array}$ & $\begin{array}{c}\text { SR50+ } \\
\text { SF }\end{array}$ & $\begin{array}{c}\mathbf{p} \\
\text { (Fisher) }\end{array}$ \\
\hline & Não & 8 & 80,0 & 10 & 100,0 & 8 & 80,0 & 9 & 90,0 & 0,7264 \\
& Sim & 2 & 20,0 & 0 & 0,0 & 2 & 20,0 & 1 & 10,0 & \\
\hline
\end{tabular}

Os dados estão expressos como porcentagem da amostra. 


\subsection{Pressão arterial sistólica}

A PAS foi avaliada no início, durante a indução da anestesia, antes e após a IOT. A análise estatística revelou diferença significante entre o grupo SR50+SF e SR50+Clonidina, e entre o grupo S75R25+Clonidina e SR50+Clonidina antes da IOT. Após a IOT houve diferença significante entre - grupo S75R25+Clonidina e SR50+Clonidina, e entre o grupo S75R25+Clonidina e S75R25+SF. Quando se comparou a PAS inicial com aquela medida imediatamente antes e após a IOT, houve diferença significante nos grupos S75R25+SF e SR50+SF como pode ser visto pela figura 5 .

Figura 5 - Pressão Arterial Sistólica $(\mathrm{mmHg})$ desde o início da anestesia até a intubação traqueal.

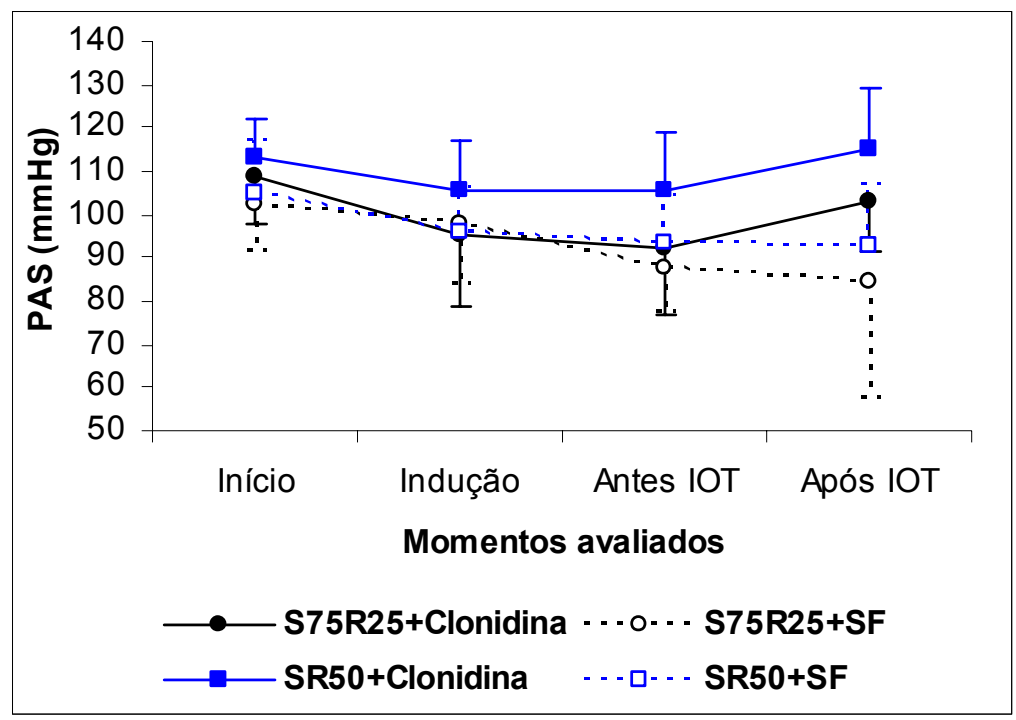

No eixo das abscissas estão dispostos os momentos de avaliação e no eixo das ordenadas os valores da PAS exibidos como média e desvio padrão.

A PAS avaliada durante 0 procedimento revelou 0 mesmo comportamento entre o perfil médio dos valores nos grupos e momentos de avaliação, a cada 5 minutos durante a operação, como pode ser visto na figura 6 . 
Figura 6 - Pressão arterial sistólica $(\mathrm{mmHg})$ a cada 5 minutos, durante a operação.

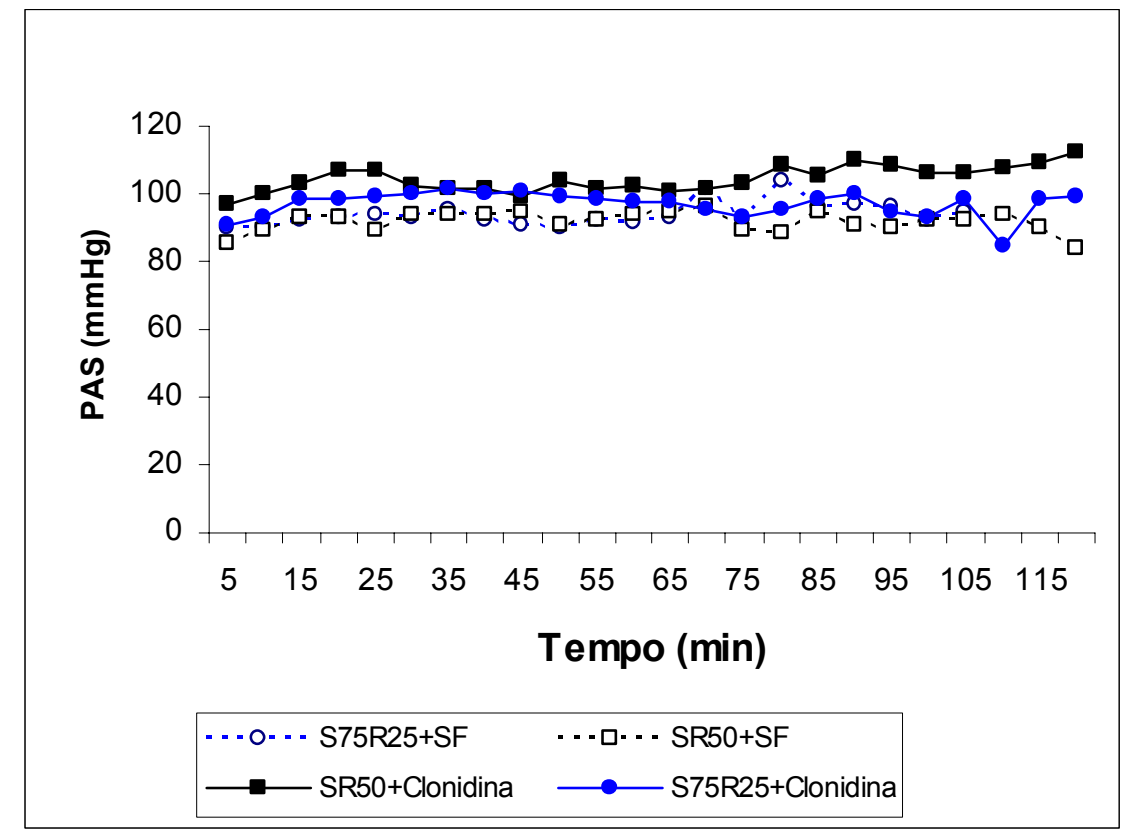

No eixo das abscissas estão representados os momentos de avaliação a cada 5 minutos durante o procedimento. No eixo das ordenadas o perfil médio dos valores da PAS $(\mathrm{mmHg})$.

A PAS avaliada após o término do procedimento revelou na $1^{\mathrm{a}} \mathrm{h}$ diferença significante entre os grupos S75R25+Clonidina e S75R25+SF. Os valores da PAS na $1^{\text {a }} \mathrm{h}$ foram menores nos grupos: SR50+Clonidina e S75R25+Clonidina, porém estes não foram significativos quando submetidos ao tratamento estatístico. Quando se comparou a PAS entre momentos diferentes ( $1^{\mathrm{a}}$ e $\left.8^{\mathrm{a}} \mathrm{h}\right)$ no mesmo grupo, houve diferença significante no grupo S75R25+Clonidina. Apesar de não haver significância estatística, na $8^{\mathrm{a}} \mathrm{h}$ de observação no pós-operatório, ambos os grupos que utilizaram clonidina apresentaram valores menores da PAS, como pode ser visto pela figura 7 . 
Figura 7 - Pressão arterial sistólica $(\mathrm{mmHg})$ no período pósoperatório.

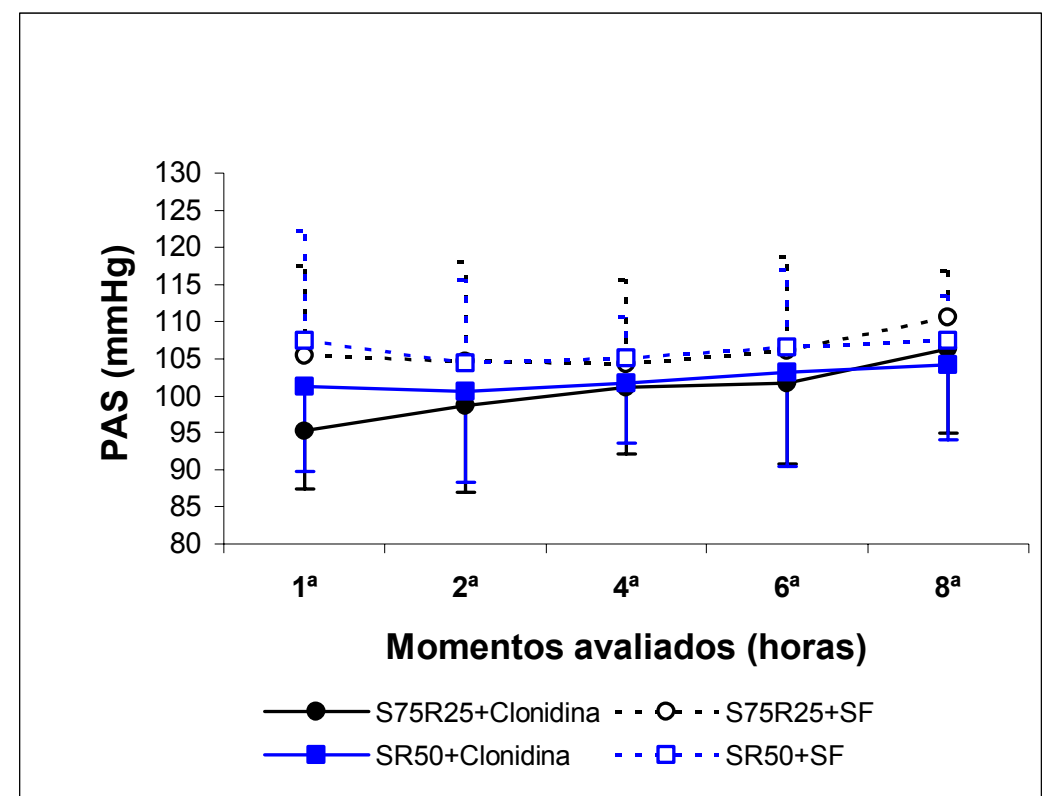

No eixo das abscissas estão representados os momentos de avaliação no pós-operatório, no eixo das ordenadas os valores da PAS, exibidos como média e desvio padrão. 


\subsection{Freqüência cardíaca}

A FC foi avaliada no início e durante a indução da anestesia, e antes e após a IOT. A análise estatística não revelou diferença entre os grupos quando comparados nos mesmos momentos. Quando se comparou a FC inicial com aquela medida imediatamente após a IOT, houve elevação significativamente estatística dos valores em todos os grupos, como pode ser visto pela figura 8 .

Figura 8 - Freqüência cardíaca (bpm) até a intubação traqueal.

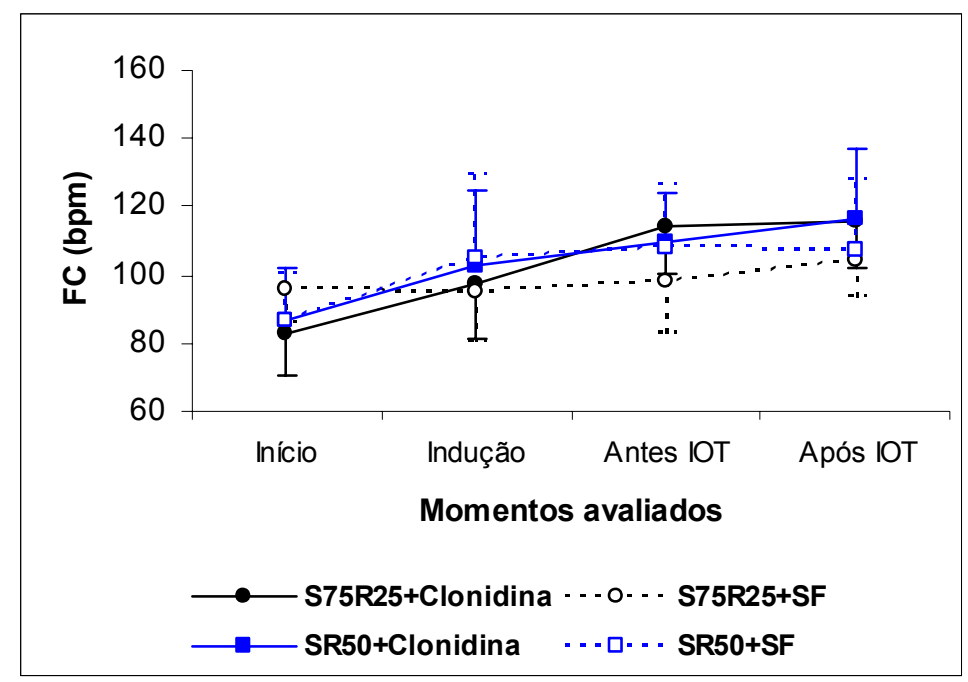

No eixo das abscissas estão representados os momentos avaliados, e no eixo das ordenadas os valores da FC (bpm) exibidos como média e desvio padrão.

A FC avaliada durante o procedimento revelou semelhança de comportamento no perfil da média dos valores obtidos nos grupos, nos momentos avaliados, como pode ser visto pela figura 9 . 
Figura 9 - Freqüência Cardíaca (bpm), avaliada a cada 5 minutos durante o procedimento.

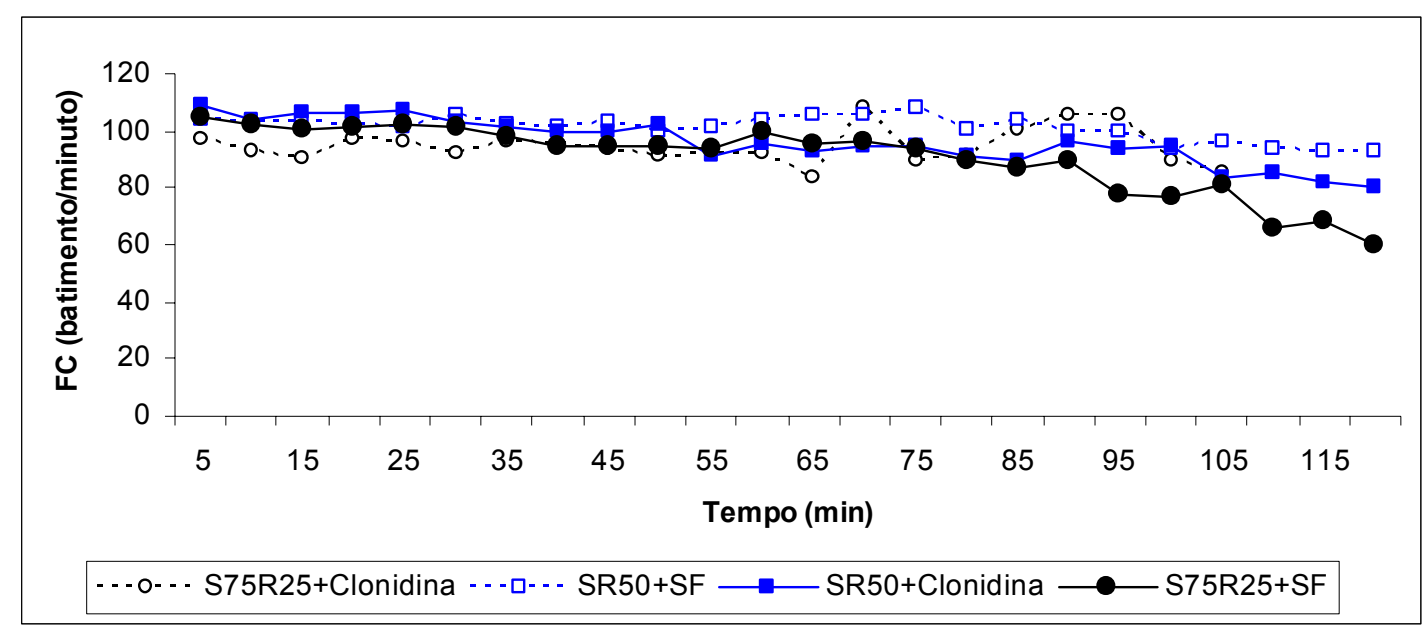

No eixo das abscissas estão representados os momentos avaliados durante o procedimento a cada 5 minutos e no eixo das ordenadas a média dos valores da FC.

A FC avaliada após o término do procedimento na primeira e segunda hora revelou diferença estatisticamente significante entre os grupos S75R25+SF e SR+Clonidina quando comparado com S75R25+Clonidina. $\mathrm{Na} 4^{\mathrm{a}} \mathrm{h}$ os valores da FC foram significativamente menores no grupo S75R25+Clonidina comparado aos do grupo S75R25+SF. Nos demais momentos não houve diferença estatisticamente significante entre os grupos. Quando foram comparados os momentos, houve diferença estatisticamente significante no grupo S75R25+Clonidina entre a $1^{\mathrm{a}}$ e $8^{\mathrm{a}} \mathrm{h}$ como pode ser visto pela figura 10. 
Figura 10 - Freqüência Cardíaca (bpm) no período pósoperatório.

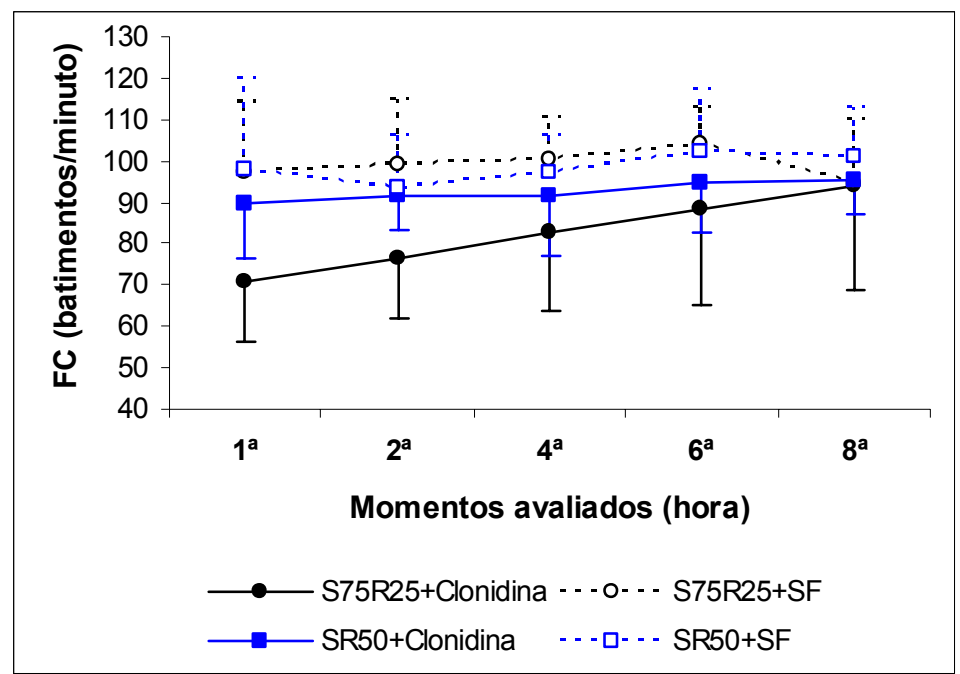

No eixo das abscissas estão representados os momentos de avaliação no pós-operatório e exibidos em horas e no eixo das ordenadas os valores da FC exibidos como média e desvio padrão. 


\subsection{Saturação periférica de oxigênio}

A $\mathrm{SpO}_{2}$ foi avaliada no início e durante a indução da anestesia, antes e após a IOT. A análise estatística revelou diferença estatisticamente significante entre o grupo S75R25+SF comparado ao S75R25+Clonidina, na indução da anestesia. Entretanto, clinicamente essa diferença não é significante. Houve diferença significante quando se comparou a $\mathrm{SpO}_{2}$ inicial com aquela medida imediatamente após a IOT, como pode ser visto pela figura 11 nos grupos S75R25+Clonidina e SR50+SF.

Figura 11 - Saturação periférica de oxigênio (em porcentagem) até a intubação traqueal.

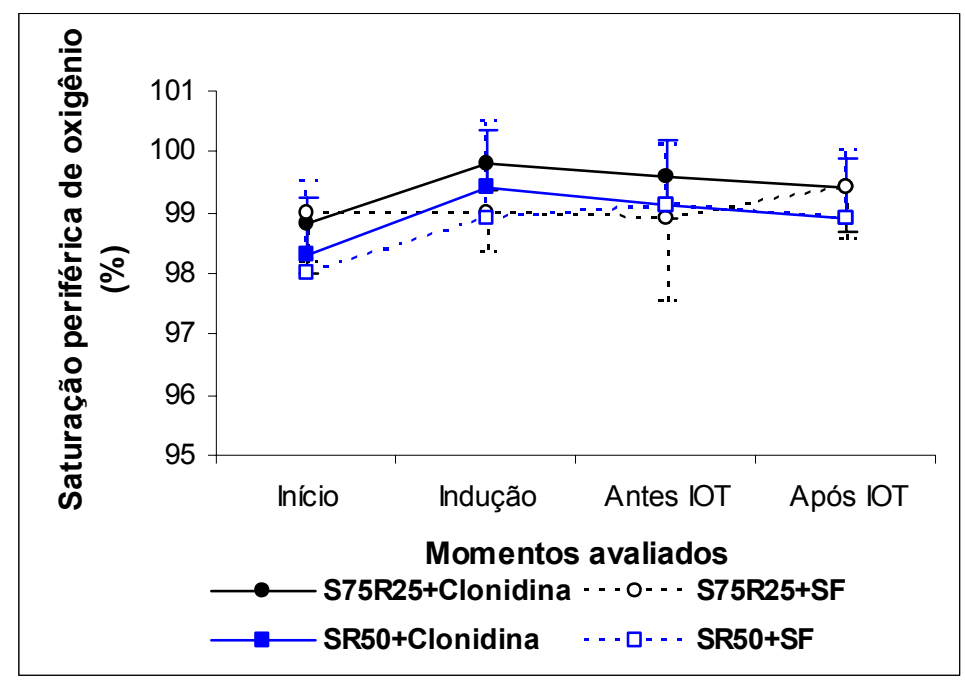

No eixo das abscissas estão representados os momentos avaliados durante o estudo e no eixo das ordenadas os valores de $\mathrm{SpO}_{2}$ exibidos como média e desvio padrão, expressos em porcentagem. 
A $\mathrm{SpO}_{2}$ avaliada a cada 5 minutos revelou comportamento semelhante aos valores obtidos nos grupos SR50+SF, SR50+Clonidina e S75R25+Clonidina, como pode ser visto pela figura 12 .

Figura 12 - Saturação periférica de oxigênio (em porcentagem), medida a cada 5 minutos durante a operação.

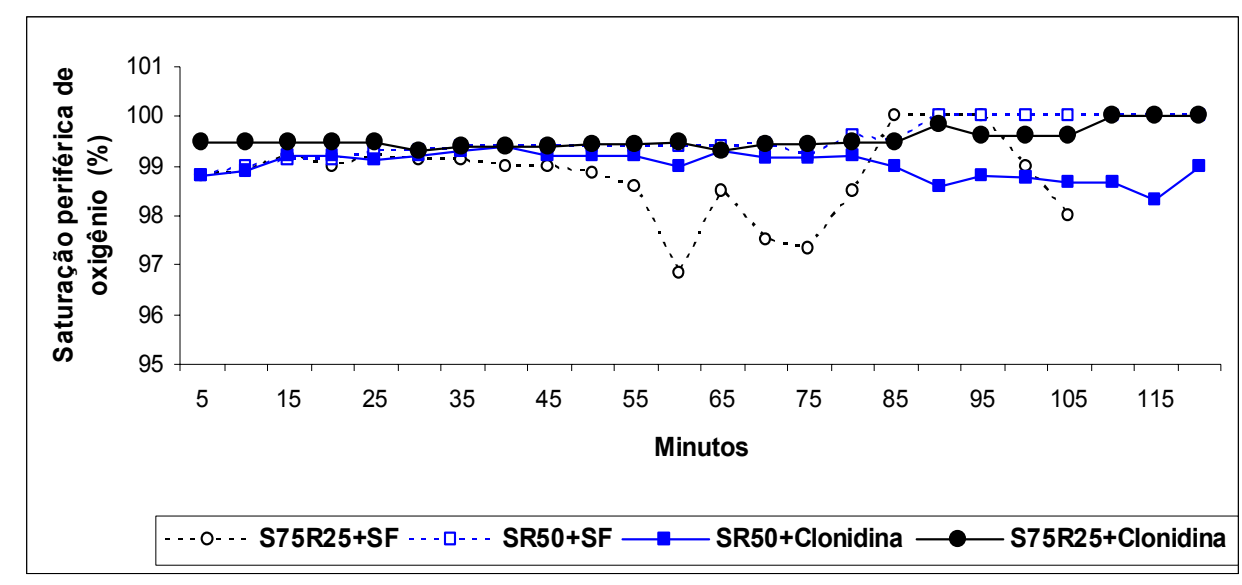

No eixo das abscissas estão representados os momentos de avaliação durante procedimento e no eixo das ordenadas a média em porcentagem. 


\subsection{Fração expirada de dióxido de carbono}

A $\mathrm{EtCO}_{2}$ foi avaliada após a IOT e durante o ato anestésicocirúrgico. A análise estatística não revelou diferença entre os grupos. Os grupos exibiram comportamento semelhante no perfil médio dos valores obtidos pela avaliação a cada 5 minutos, como pode ser verificado pela tabela 16 e pela figura 13 .

Tabela 16 - Fração expirada de dióxido de carbono, em $\mathrm{mmHg}$, avaliada após a intubação traqueal.

\begin{tabular}{lccccccc}
\hline \multicolumn{1}{c}{ Grupo } & n & Mínimo & Máximo & Mediana & Média & DP & p \\
\hline S75R25+Clonidina & 10 & 24,00 & 58,00 & 45,50 & 42,30 & 11,04 & 0,6545 \\
S75R25+SF & 7 & 40,00 & 50,00 & 44,00 & 44,43 & 3,64 & \\
SR50+Clonidina & 9 & 32,00 & 60,00 & 47,00 & 46,11 & 9,49 & \\
SR50+SF & 8 & 36,00 & 58,00 & 47,50 & 47,25 & 7,74 & \\
\hline
\end{tabular}

Figura 13 - Fração expirada de dióxido de carbono em $\mathrm{mmHg}$, medida a cada 5 minutos durante a operacão.

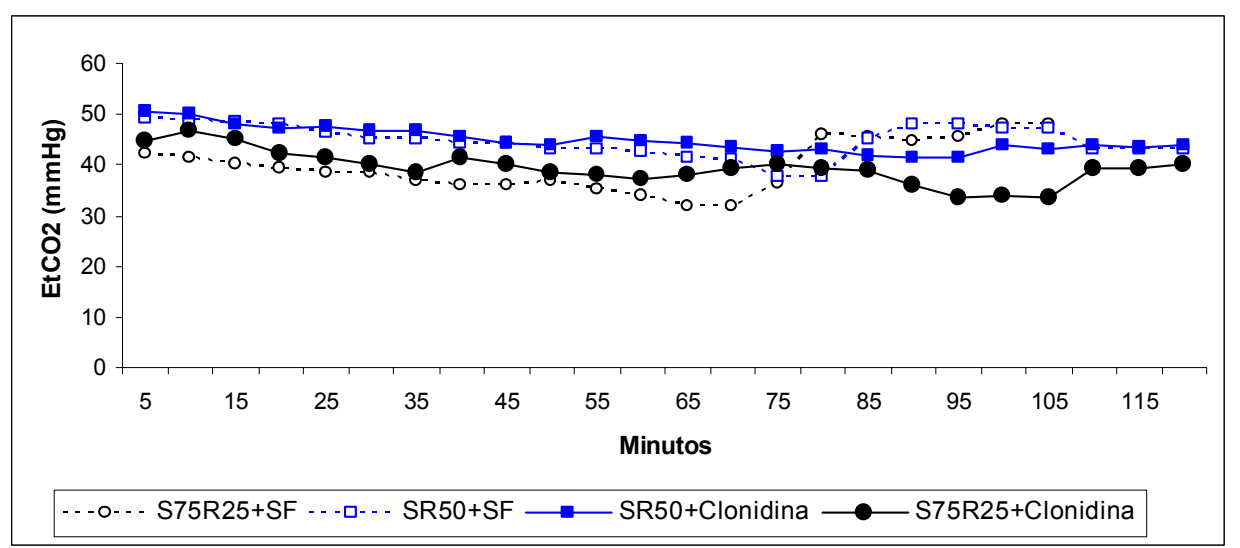

No eixo das abscissas estão representados os momentos avaliados a cada 5 minutos, no eixo das ordenadas a média dos valores da $\mathrm{EtCO}_{2}$ expressos em $\mathrm{mmHg}$. 


\subsection{Sedação durante o pós-operatório.}

A sedação durante o período pós-operatório teve comportamento semelhante em todos os grupos estudados até a $4^{\mathrm{a}} \mathrm{h}$ de avaliação. Porém, na $6^{\mathrm{a}} \mathrm{h}$ a sedação foi menos acentuada e estatisticamente significante no grupo S75R25+SF comparado com os demais grupos, como pode ser visto pela figura 14 .

Figura 14 - Sedação durante o pós-operatório.

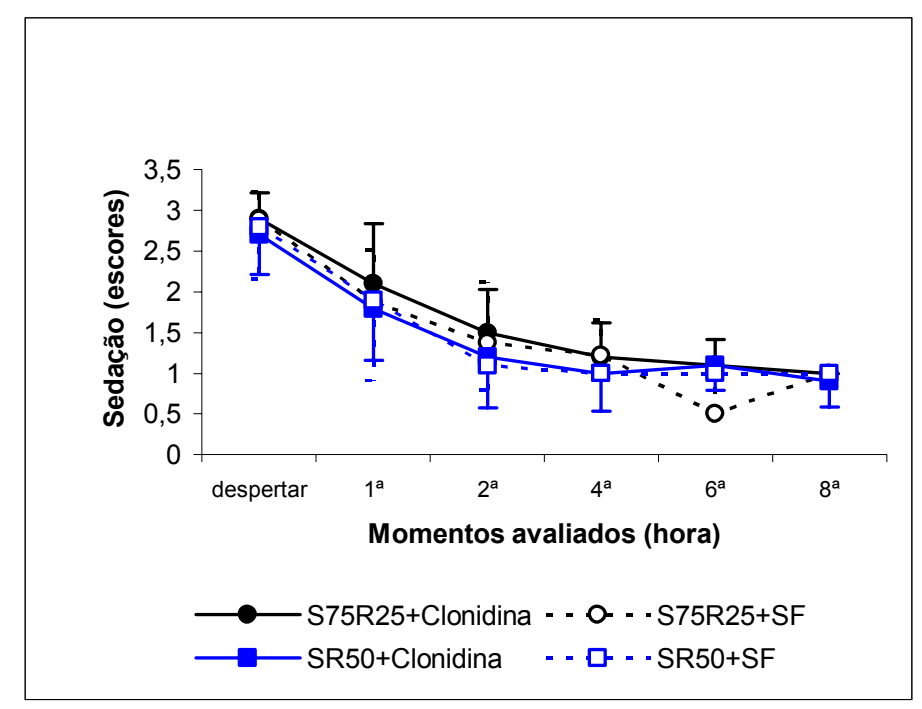

No eixo das abscissas estão dispostos os momentos de avaliação no pós-operatório e no eixo das ordenadas estão os valores obtidos em cada grupo e exibidos como média e desvio padrão. 


\subsection{Eventos adversos}

Os eventos adversos náuseas e vômitos não estiveram presentes no grupo SR50+SF, mas a sua incidência foi de 20 a $30 \%$ nos outros grupos. Houve alterações respiratórias nos grupos S75R25+SF e SR50+Clonidina, porém sem gravidade e a incidência foi de $10 \%$ no grupo SR50+Clonidina e de $20 \%$ no grupo S75R25+SF, como pode ser visto na tabela 17. A análise estatística não detectou diferença significante.

Tabela 17 - Alterações respiratórias, náuseas e vômitos.

\begin{tabular}{llccccccccc}
\hline & & \multicolumn{2}{c}{$\begin{array}{c}\text { S75R25+ } \\
\text { Clonidina }\end{array}$} & $\begin{array}{c}\text { S75R25+ } \\
\text { SF }\end{array}$ & $\begin{array}{c}\text { SR50+ } \\
\text { Clonidina }\end{array}$ & $\begin{array}{c}\text { SR50+ } \\
\text { SF }\end{array}$ & p \\
\hline Variável & Categoria & $\mathrm{n}$ & $\%$ & $\mathrm{n}$ & $\%$ & $\mathrm{n}$ & $\%$ & $\mathrm{n}$ & $\%$ & (Fisher) \\
\hline \multirow{2}{*}{ Náusea } & Não & 7 & 70,0 & 8 & 80,0 & 7 & 70,0 & 10 & 100,0 & 0,3077 \\
& $\mathrm{Sim}$ & 3 & 30,0 & 2 & 20,0 & 3 & 30,0 & 0 & 0,0 & \\
\hline \multirow{2}{*}{ Vômito } & Não & 7 & 70,0 & 8 & 80,0 & 7 & 70,0 & 10 & 100,0 & 0,3077 \\
& Sim & 3 & 30,0 & 2 & 20,0 & 3 & 30,0 & 0 & 0,0 & \\
\hline \multirow{2}{*}{$\begin{array}{l}\text { Alterações } \\
\text { respiratórias }\end{array}$} & Não & 10 & 100,0 & 7 & 70,0 & 9 & 90,0 & 10 & 100,0 & 0,1668 \\
& Sim & 0 & 0,0 & 2 & 20,0 & 1 & 10,0 & 0 & 0,0 & \\
\hline
\end{tabular}

Eventos adversos descritos como porcentagem de ocorrência em cada grupo estudado. 
5. DISCUSSÃO 
A associação da anestesia regional com a geral para procedimentos ambulatoriais é a preferida para os pacientes pediátricos. Os bloqueios periféricos, tem ampla aceitação para os procedimentos ambulatoriais porém, apresentam limitações relacionadas à massa e ao volume de anestésico local necessários para a sua realização, com a possibilidade de falha técnica que poderá comprometer a analgesia cirúrgica e pós-operatória.

A realização de bloqueio central pode minimizar a limitação ao uso de bloqueios periféricos, porém essa técnica não é destituída de limitações ou complicações.

A hipótese que motivou este estudo teve cunho prático e está relacionada à realização de anestesia regional em crianças submetidas a operações ambulatoriais que não necessitam de internação hospitalar. 0 objetivo foi avaliar se a técnica anestésica peridural sacra com o anestésico local bupivacaína S75R25 é tão eficaz como a realizada com a bupivacaína SR50, associada ou não a clonidina, para promover anestesia e diminuir o consumo de fármacos anestésicos no perioperatório, bem como proporcionar analgesia e conforto no pós-operatório para esses pacientes. $\mathrm{O}$ relaxamento da musculatura dos membros inferiores no período pósoperatório, especialmente em crianças menores é desconfortável e é também fator que retarda a alta hospitalar nos procedimentos ambulatoriais.

A escolha do anestésico local bupivacaína S75R25 para esta população surgiu de estudos que sugerem a utilização de anestésicos locais que apresentam em sua composição enantiômeros levógiros por serem menos tóxicos que os racêmicos (Ivani et al., 1988). 


\subsection{Limitações do estudo}

A faixa etária entre 5 e 10 anos foi a escolhida porque na fase préescolar a criança já apresenta maturidade da função motora e verbaliza a sensação desagradável de dor. As operações de pequeno porte infraumbilicais foram escolhidas porque foi estabelecido $20 \mathrm{~mL}$ como o volume máximo da solução de anestésico local a ser injetada no espaço peridural sacro. A realização de procedimentos supra-umbilicais implica na utilização de volumes iguais ou maiores a $1 \mathrm{~mL} / \mathrm{kg}$, o que em algumas crianças pode ultrapassar a dose máxima permitida para a bupivacaína SR50 ou S75R25.

A maioria dos estudos publicados utilizando bupivacaína SR50 e levobupivacaína, obedeceram a dose máxima de $3 \mathrm{mg} / \mathrm{kg}$ para adultos, sendo que alguns autores preconizam para crianças a dose máxima de 2 $\mathrm{mg} / \mathrm{kg}$, em função do perfil farmacodinâmico da bupivacaína e da associação com anestesia geral, que pode mascarar o aparecimento dos sintomas e sinais de toxicidade no sistema nervoso central. (Ecoffey et al., 1985; Karmakar et al., 2002).

Se anestésico local utilizado é a bupivacaína SR50, podem ocorrer arritmias graves, colapso cardiovascular e parada cardíaca de difícil resposta às manobras habituais de ressuscitação cardíaca quando injetados acidentalmente no vaso sanguíneo. (Albright, 1979).

A escolha do anestésico local para operações ambulatoriais é muito importante, sendo indicado um agente de longa duração devido a impossibilidade de manter cateter no espaço peridural no pós-operatório, porém os agentes de duração longa apresentam toxicidade sistêmica aumentada.

A utilização da ropivacaína, anestésico com longa duração, apresentado em solução contendo apenas o isômero S-, é benéfica em 
pacientes pediátricos. (Conceição e Coelho, 1998; Ivani et al., 1998 Conceição et al., 1999).

No país, estão liberadas para uso clínico a bupivacaína racêmica SR50, a ropivacaína e a bupivacaína S75R25. Experimentalmente, a bupivacaína S75R25 comprovou ser de longa duração e apresentar menor incidência de efeitos tóxicos sistêmicos do que a bupivacaína racêmica (Ferreira, 1999; Simonetti e Ferreira, 1999; Simonetti e Bird, 2000; Simonetti et al. 2000).

Em estudos clínicos a bupivacaína \$75R25 mostrou eficácia anestésica local em pacientes adultos para vários procedimentos operatórios. (Delfino e Vale, 2001; Imbelloni e Beato, 2001; Cortês et al., 2003; Tanaka et al., 2003).

Existe apenas um estudo realizado em crianças com a bupivacaína S75R25 em anestesia intratecal em crianças de 1 a 5 anos. Embora não tenha havido grupo controle os resultados desse estudo foram favoráveis quando se considerou a duração de ação e a eficácia do bloqueio motor.(Imbelloni et al., 2002).

O presente estudo, prospectivo, aleatório e duplamente encoberto, foi realizado em crianças de 5 a 10 anos, submetidas a operações infraumbilicais de pequeno porte. A bupivacaína S75R25 foi escolhida para a realização de anestesia peridural sacra nestes pacientes, por se tratar de um agente de longa duração e toxicidade sistêmica diminuída. (Simonetti et al., 1997b; Ferreira, 1999; Simonetti e Ferreira, 1999; Simonetti e Bird, 2000; Simonetti et al. 2000).

As limitações impostas para a realização de um estudo clínico são muitas, e quase sempre relacionados à dificuldade de inclusão dos pacientes e à coleta de dados (Ivani et al. 2003). Assim, a interpretação dos 
resultados deve ser cautelosa sob o ponto de vista estatístico, especialmente quando o número de pacientes é pequeno, pois um resultado pode apresentar significância estatística, porém sem relevância clínica.

Nesta investigação houve prevalência da população masculina devido ao tipo de procedimento cirúrgico incluído. A mesma distribuição preferencialmente masculina também foi observada por outros autores (Ivani et al., 2003; Joshi et al., 2004). Doenças como fimose, hipospádia, hidrocele e criptorquidia são exclusivas do sexo masculino, já a hérnia inguinal embora presente no sexo feminino, tem prevalência no masculino devido à presença do canal inguinal que pode permanecer pérvio. Todas essas doenças podem ser tratadas com operações em regime ambulatorial realizadas sob anestesia peridural sacral (Velhote, 2003). Apesar da prevalência do sexo masculino no estudo, a sua distribuição foi uniforme nos grupos estudados.

A distribuição aleatória dos pacientes nos grupos incluiu maior número de procedimentos potencialmente mais dolorosos nos grupos em que a clonidina foi associada aos anestésicos locais estudados. Esse fato deve ser considerado ao analisar a semelhança dos resultados relativos a analgesia, quando se comparou os grupos que receberam a clonidina e aqueles, que receberam apenas placebo.

A informação fornecida pelo responsável após $24 \mathrm{~h}$ do término da operação, foi obtida pelo pesquisador por contato telefônico. O responsável legal pela criança foi orientado quanto às anotações que deveria fazer, e estas informações foram registradas e analisadas. Este tipo de avaliação também foi utilizada por Klimscha et al. (1998), e Joshi et al. (2004) em estudos que incluíram procedimentos ambulatoriais em crianças, e as anotações feitas pelos responsáveis foram analisadas e fizeram parte dos registros em sua apresentação final. 
O prolongado tempo para a coleta de dados desta pesquisa e o pequeno número de pacientes incluídos deveu-se às dificuldades encontradas para a inclusão dos pacientes e para a coleta de dados durante o período pré, peri e pós-operatório. Contudo, não houve exclusão por violação do protocolo.

\subsection{Considerações sobre o bloqueio motor e a analgesia}

As 40 crianças incluídas e a distribuição aleatória nos 4 grupos, permitiu investigar a intensidade e duração do bloqueio motor e a duração da analgesia no perioperatório produzidas pelos anestésicos locais SR50 e S75R25 associados ou não a clonidina, quando administrados no espaço peridural sacral.

Quando se considerou a analgesia induzida pela bupivacaína S75R25 sem adjuvante houve preservação da propriedade anestésica local sem diferença significante na duração da analgesia quando comparada com a bupivacaína SR50. Foi possível verificar que os resultados foram semelhantes aos dos estudos realizados com a bupivacaína SR50, a levobupivacaína e com a ropivacaína em crianças, sem diferença significante entre a duração da analgesia produzida pelos anestésicos locais na forma racêmica e enantiomérica. (Ivani et al., 1998; Ivani e De Negri, 2001; Ivani et al., 2002; Astuto et al., 2002; De Negri et al., 2004).

Esse resultado foi atribuído às diferenças farmacocinéticas e farmacodinâmicas da forma levógira da bupivacaína no bloqueio das fibras nervosas, e sugere que as fibras $A \delta$ e $C$ são mais susceptíveis ao bloqueio pela forma levógira, o que explica a diminuição do bloqueio motor quando comparado ao bloqueio induzido pela bupivacaína SR50. (Ivani et al., 1998; Ivani e De Negri, 2001; Ivani et al., 2002; Astuto et al., 2002; De Negri et al., 2004). 
A avaliação do bloqueio motor demonstrou que o grupo SR50 associado a clonidina apresentou na primeira hora de avaliação no pósoperatório, bloqueio mais intenso e significativo em relação aos demais grupos estudados. Apesar, do bloqueio motor neste grupo ter se prolongado além da quarta hora, estes valores não foram significativos quando submetidos ao tratamento estatístico.

A associação de clonidina a bupivacaína S75R25 não prolongou o bloqueio motor. Este resultado ratifica a indicação deste anestésico local em anestesia regional pediátrica, porque o bloqueio motor prolongado dificulta a interpretação da nocicepção pelas crianças menores, que podem confundir o desconforto do bloqueio motor com aquele produzido pela dor e porque pode retardar a alta hospitalar em procedimentos ambulatoriais.

Outros estudos também confirmaram a diminuição da intensidade e da duração do bloqueio motor após bloqueio peridural sacro em crianças, quando foram utilizadas formulações enantioméricas puras como a ropivacaína (Koinig et al., 1999; Luz et al., 2000; Bosenberg et al., 2002; Locatelli et al., 2005) e a levobupivacaína (Ivani et al., 2002; Astuto et al., 2002; Taylor et al., 2003; De Negri et al., 2004; Locatelli et al., 2005) É pequeno o número de trabalhos com a levobupivacaína via peridural sacra em crianças disponível na literatura médica mundial, muito possivelmente porque até $\mathrm{o}$ momento o fármaco está disponível em poucos países. (Locatelli et al., 2005).

Neste estudo, a duração da analgesia foi definida como o tempo decorrido entre a administração dos anestésicos locais no espaço peridural sacro e a primeira dose de resgate de analgésico. A adoção deste critério foi baseada em estudos prévios realizados em crianças, nos quais foi investigada a duração da analgesia produzida por anestésicos locais. 
(Jamali et al., 1994; Cook et al., 1995; Klimscha et al., 1998; Nishina et al., 1999; Ivani et al., 2000; De Negri et al., 2001).

Embora, a duração da analgesia tenha sido maior no grupo que recebeu a bupivacaína SR50 associada com a clonidina, os resultados não foram estatisticamente significantes quando comparados aos grupos onde a clonidina não foi adicionada e ao grupo S75R25+Clonidina.

Os resultados da associação da clonidina com anestésicos locais na peridural sacra em crianças com o objetivo de melhorar a qualidade $e$ duração da analgesia pós-operatória não são uniformes, e são ainda bastante controversos. Nos trabalhos encontrados na literatura a dose de clonidina na peridural sacra em crianças variou de 1 a $5 \mu \mathrm{g} / \mathrm{kg}$.

Os estudos demonstraram que a duração da analgesia pósoperatória variou de 5,8 a 16,5 horas quando a clonidina na dose de 1 ou $2 \mu \mathrm{g} / \mathrm{kg}$ foi associada a bupivacaína na peridural sacra de crianças submetidas a operações infra-umbilicais. A duração foi mais prolongada quando comparada com a bupivacaína sem adjuvante. Outros autores, atribuíram as diferenças nos resultados à dose de clonidina usada, à diferenças na medicação pré-anestésica, aos anestésicos inalatórios associados, ao tipo de operação, às indicações para a aplicação do analgésico de resgate, aos métodos usados para a avaliação da dor e a análise estatística.(Jamali et al., 1994; Cook et al., 1995; De Beer e Thomas 2003).

Motsch et al. (1997) usaram $5 \mu \mathrm{g} / \mathrm{kg}$ de clonidina associada com bupivacaína via peridural sacra para operações de pequeno porte como hérnia inguinal, orquipexia e hipospádia, e a duração da analgesia pósoperatória foi de 20,9 horas, portanto mais longa que a das pesquisas onde a dose utilizada não superou $2 \mu \mathrm{g} / \mathrm{kg}$. 
A duração da analgesia quando 1 a $2 \mu \mathrm{g} / \mathrm{kg}$ de clonidina foram associados a ropivacaína, foi menor do que quando ela foi associada a bupivacaína. (Ivani et al., 2000; De Negri et al., 2001).

Entretanto, Joshi et al. (2004) não conseguiram demonstrar aumento da analgesia quando associaram clonidina na dose de 1 a $2 \mu \mathrm{g} / \mathrm{kg}$ a bupivacaína $0,125 \%$ via peridural sacra, para operações de pequeno porte em crianças. Esses autores atribuíram o resultado à baixa concentração de bupivacaína ou a escala adotada para avaliação da dor e da sedação, que podem mascarar a necessidade do tratamento medicamentoso da dor.

O mecanismo preciso pelo qual a clonidina prolonga a analgesia no pós-operatório, ainda não está completamente elucidado. Um dos mecanismos sugeridos é que a clonidina no espaço peridural exerça ação analgésica pela supressão direta da atividade dos neurônios nociceptivos no corno dorsal da medula espinhal. Outro mecanismo sugerido é que a clonidina atravessa facilmente a barreira sangue-cérebro para interagir com os adrenoceptores a envolvidos na ativação de proteínas transmembrana inibitórias (proteína G), nas regiões espinhal e supra-espinhal do sistema nervoso central. (Kamibayashi e Maze, 2000)

Perifericamente, a clonidina inibe a neurotransmissão nas fibras nervosas do tipo $A \delta$ e $C$. Um mecanismo mediado farmacocinéticamente também é sugerido, segundo o qual a vasoconstrição induzida pela clonidina por sua ação em receptores adrenérgicos $a 2 b$, promove aumento do tempo de contato do anestésico local com a fibra nervosa, contribuindo para o aumento da duração da analgesia. (Butterworth e Strichartz, 1993; Simonetti et al., 1997a; Nishina e Mikawa, 2002). Além disso, Lawhead et al. (1992) e Smith et al. (1995) demonstraram que os receptores responsáveis pela analgesia induzida pela clonidina (a2a), constituem 80 a $90 \%$ da população dos receptores a2 cuja distribuição na espécie humana é predominante em região sacral da medula espinhal. 
Neste estudo não foi possível detectar diferença significante entre os grupos que receberam a clonidina e o placebo quando se comparou o tempo decorrido entre a sua administração e a primeira dose de analgésico usado como resgate. Esse resultado talvez possa ser explicado pelo tipo de operação potencialmente menos dolorosa aleatoriamente distribuída nos grupos que receberam anestésico local com placebo, enquanto que, nos grupos onde a clonidina foi associada, as operações foram potencialmente mais dolorosas.

Outra consideração a fazer é que, deste estudo só participaram crianças submetidas a operações de porte cirúrgico pequeno, sem necessidade de internação hospitalar. Este também foi um fator limitante para a avaliação da analgesia pós-operatória, porque as operações em regime ambulatorial geralmente são pouco dolorosas, e também foram incluídas operações que não necessitassem de qualquer tipo de opióide para a analgesia pós-operatória, com o objetivo de evitar os efeitos adversos que exigem internação, o que aumenta o custo hospitalar e diminui a satisfação da criança e do responsável.

Os resultados mostram a necessidade da realização de estudos dose-resposta com várias doses de clonidina, assim como com várias concentrações e volumes de anestésicos locais em crianças submetidas a operações que necessitem de internação hospitalar e de analgesia pósoperatória mais potente.

Nishina e Mikawa (2002) realizaram revisão da literatura e concluíram que é necessário um estudo amplo, multicêntrico, prospectivo, duplamente encoberto e aleatório para determinar se a clonidina é vantajosa como adjuvante na anestesia regional, quanto ao aumento da duração da analgesia pós-operatória. 
No presente estudo, foi avaliado o número de pacientes que necessitaram de analgésico após a alta hospitalar. Esta informação foi obtida por contato telefônico com o responsável pela criança. Quando esses dados foram analisados pelo teste exato de Fisher, não houve diferença significativa entre os grupos. O número de doses de analgésico usado na residência também não foi diferente quando os grupos foram comparados entre si, de acordo com o teste de Kruskal-Wallis. Apesar do resultado não ser estatisticamente significante os grupos nos quais a clonidina foi utilizada necessitaram de maior número de doses de analgésico na residência, talvez devido ao tipo de operação potencialmente mais dolorosa neles realizada.

A clonidina possui efeito sedativo central, quando administrada sistêmica ou centralmente em bloqueio neuroaxial. Esse efeito parece envolver a ativação de receptores $\alpha 2$ adrenérgicos supramedulares localizados na região do locus coeruleus, responsável pelo estado de vigília.(Nishina et al., 1999)

A sedação no pós-operatório foi semelhante em todos os grupos estudados até a sexta hora de avaliação, e apenas nesse momento, as crianças no grupo S75R25 apresentaram escores menores de sedação em relação aos demais grupos, porém, essa diferença não foi estatisticamente significante. Os valores para sedação na primeira e segunda hora de avaliação não podem ser atribuídos a clonidina, já que não houve diferença entre os grupos. A sedação encontrada nesses momentos de avaliação em todos os grupos pode ser devida ao efeito residual do midazolam utilizado como medicação pré-anestésica, ou mesmo ao efeito da analgesia promovida pelos anestésicos locais empregados no bloqueio caudal.

De Mey et al. (2000) e Sharpe et al. (2001) não detectaram aumento da duração da analgesia em seus estudos com a utilização de clonidina via peridural sacra em crianças. Sharpe et al. (2001) utilizaram para a avaliação da dor escala de 3 critérios, que parece não ser bastante sensível para 
detectar pequenas diferenças entre os grupos.(Nishina e Mikawa, 2002) Além disso, verificaram a existência de um efeito sedativo dose-dependente nas crianças que receberam $2 \mu \mathrm{g} / \mathrm{kg}$ de clonidina sacral, com aumento significativo no tempo para despertar (Sharpe et al., 2001).

Neste estudo não houve diferença significativa entre os grupos quanto à sedação pós-operatória ou ao tempo decorrido entre a retirada do tubo traqueal e o despertar. Estes dados parecem não ter correlação direta com a utilização da clonidina via peridural sacra, pois todos os grupos exibiram o mesmo comportamento em relação à sedação pós-operatória, não obstante em todas as crianças o tubo traqueal tenha sido retirado em plano anestésico profundo, para evitar erro na avaliação do tempo para despertar.

\subsection{Clonidina e consumo de sevoflurano}

As concentrações de sevoflurano foram registradas do inicio da indução até a intubação traqueal e depois da intubação traqueal até o fim da operação. Todos os grupos apresentaram diminuição estatisticamente significativa da concentração de sevoflurano após a intubação traqueal quando comparada ao momento até intubação traqueal, porém, quando os grupos foram comparados, não houve diferença estatisticamente significante.

A diminuição da concentração de sevoflurano pode ter correlação com o bloqueio regional, pois é sabido que a anestesia regional pode reduzir o consumo de anestésicos inalatórios e endovenosos, mas não parece estar relacionada somente à adição de clonidina. Não é possível inferir nesse estudo, que a clonidina tenha sido responsável pela diminuição da concentração do sevoflurano utilizada a partir da intubação traqueal, já que essa diminuição não foi significativa nos grupos onde a clonidina foi usada, comparada aos grupos onde somente foi aplicado anestésico local. 


\subsection{Eventos adversos}

Os eventos adversos registrados durante o estudo foram submetidos à análise estatística pelo teste exato de Fisher, e não foi possível detectar diferença significativa na incidência de náusea e vômito entre os grupos. Houve duas complicações respiratórias no grupo S75R25, e uma no grupo SR50+ Clonidina, contudo estas foram sem gravidade e significância clínica ou estatística, e não podem ser atribuídas a clonidina. Finalmente, a $\mathrm{EtCO}_{2}$ não mostrou diferença significante quando comparada entre os grupos durante o estudo. Este resultado permite inferir que a clonidina não promoveu depressão respiratória.

Existe na literatura relato de três casos isolados nos quais a clonidina foi responsabilizada por depressão respiratória em lactentes com história pregressa de prematuridade e intubação traqueal após 0 nascimento.(Bouchut et al., 2001; Fellmann et al., 2002; Hussain et al., 2003) É importante destacar que do presente estudo somente participaram crianças em idade pré-escolar e escolar, sendo que nenhuma delas apresentava história de prematuridade e ou intubação traqueal após o nascimento.

\subsection{Considerações sobre as variáveis hemodinâmicas pressão arterial sistólica e freqüência cardíaca.}

Alguns autores atribuem à clonidina a estabilidade cardiovascular exibida no perioperatório de pacientes adultos e crianças (Flacke et al., 1987; Mikawa et al., 1993; Jamali et al., 1994; Nishina et al., 1999; Nishina e Mikawa, 2002). Os resultados deste estudo não demonstraram diferença significante, entre os grupos estudados, nos valores da FC ou PAS durante o procedimento ou no pós-operatório. Nos estudos que detectaram diferença significante nos valores de PAS e FC, a clonidina foi administrada sistemicamente enquanto, neste a via de administração foi sacral. (Flacke et 
al., 1987; Mikawa et al., 1993; Hackmann et al., 2003). A resposta simpática em crianças até a idade pré-escolar difere daquela encontrada em adultos e em crianças maiores, devido a imaturidade funcional do sistema nervoso simpático, característico dessa faixa etária, não se apresentando os efeitos hipotensivos da simpatectomia promovida pelos anestésicos locais utilizados nos bloqueios centrais.

Existe relato de caso de pós-operatório de correção cirúrgica de tetralogia de Fallot em criança, na qual a clonidina via peridural sacra foi usada com sucesso no tratamento de episódio de vasoconstrição sistêmica grave e refratária ao tratamento com vasodilatadores convencionalmente utilizados (Diaz e Cantu, 2003).

Os valores da PAS e FC durante o período de observação de 8 h no pós-operatório foram menores em todos os momentos, apesar de não haver significância estatística. Se a amostra populacional do estudo fosse maior, esta observação poderia ser significante e relacionada a clonidina usada no bloqueio regional.

\subsection{Considerações finais}

Este estudo comprovou a eficácia anestésica local da bupivacaína S75R25 para anestesia sacral em crianças, e que a associação com a clonidina não intensificou ou prolongou o bloqueio motor. A anestesia caudal é técnica de fácil realização, sendo este estudo um modelo de fácil reprodução e exeqüibilidade na população pediátrica. Os resultados abrem novas perspectivas para avaliar a utilidade da bupivacaína S75R25 contínua no espaço peridural, associada ou não a clonidina, ou a outro adjuvante que possa promover analgesia e conforto no pós-operatório em operação que necessite de internação hospitalar ou mais dolorosa que as deste estudo. 
O componente ansiedade é de difícil avaliação em crianças na idade pré-escolar e escolar, e ainda não foi estudado o seu controle com a utilização de agonistas $\alpha_{2}$ adrenérgicos administrados por via sistêmica ou central. Este estudo serve como um modelo para investigar a correlação entre a administração destes fármacos com a ansiedade pré e pósoperatória em crianças. 
6. CONCLUSÕES 
Nas condições em que foi realizado o presente estudo, a análise dos resultados permite inferir as seguintes conclusões:

1 - Os anestésicos locais bupivacaína S75R25 e bupivacaína SR50 apresentam perfil semelhante de bloqueio sensitivo quanto à duração de ação quando utilizados por via peridural sacra em crianças.

2 - O bloqueio motor foi mais intenso apenas na primeira hora de avaliação pós-operatória no grupo que recebeu bupivacaína SR50 associada a clonidina. Esse resultado não foi encontrado quando a bupivacaína S75R25 foi associada com clonidina.

3 - O bloqueio motor foi semelhante no grupo que recebeu bupivacaína S75R25 pura comparado com o que recebeu a bupivacaína S75R25 associada com clonidina.

4 - A clonidina usada na dose única de $2 \mu \mathrm{g} / \mathrm{kg}$, associada com os anestésicos locais bupivacaína S75R25 e bupivacaína SR50, por via peridural sacra, não promoveu aumento estatisticamente significante da analgesia pós-operatória.

5 - A clonidina usada na dose única de $2 \mu \mathrm{g} / \mathrm{kg}$, associada com os anestésicos locais bupivacaína S75R25 e bupivacaína SR50, por via peridural sacra, não causou alteração estatisticamente significante da PAS e FC no período perioperatório.

6 - A clonidina usada na dose única de $2 \mu \mathrm{g} / \mathrm{kg}$, associada com os anestésicos locais bupivacaína S75R25 e bupivacaína SR50, por via peridural sacra, não causou alteração estatisticamente significante do consumo de sevoflurano. 
7. REFERÊNCIAS BIBLIOGRÁFICAS 
Albright GA. Cardiac arrest following regional anesthesia with etidocaine and bupivacaine. Anesthesiology 1979;51:285-7.

Armitage EN. Regional anaesthesia in paediatrics. Clin Anaesth 1985;3: 553-68.

Armitage EN. Local anaesthetic techniques for prevention of postoperative pain. Br J Anaesth 1986;58:790-800.

Astuto M, Disma N, Arena C. Levobupivacaine 0,25\% compared with ropivacaine $0,25 \%$ by the caudal route in children. Eur $\boldsymbol{J}$ Anaesthesiol 2002;20:826-30.

Benzon HT, Strichartz GR, Gissen AJ, Shanks CA, Covino BG, Datta S. Developmental neurophysiology of mammalian peripheral nerves and age-related differential sensitivity to local anaesthetic. Br J Anaesth 1988; 61:754-60.

Bosenberg A, Thomas J, Lopez T, Lybeck A, Huizar K, Larsson LE. The efficacy of caudal ropivacaine 1,2 and $3 \mathrm{mg} / \mathrm{mL}$ for postoperative analgesia in children. Paediatr Anaesth 2002;12:53-8.

Bouchut JC, Dubois R, Godard J. Clonidine in preterm-infant caudal anesthesia may be responsible for postoperative apnoea. Reg Anesth Pain Med 2001;26:83-5.

Brau ME, Branitzki P, Olschewski A, Vogel W, Hempelmann G. Block of neuronal tetrodotoxin-resistant $\mathrm{Na}^{+}$currents by stereoisomers of piperidine local anesthetics. Anesth Analg 2000;91:1499-505. 
Bromage PR. Agingand epidural dose requirements. Br J Anaesth 1969;41: 1016-22.

Butterworth JF, Strichartz GR. Molecular mechanisms of local anesthesia: A review. Anesthesiology 1990;72:711-34.

Butterworth JF, Strichartz GR. The alpha 2 adrenergic agonists clonidine and guanfacine produce tonic and phasic block of conduction in rat sciatic nerve fibers. Anesthesiology 1993;76:295-301.

Cahn RS, Ingold SC, Prelog V. Specification of molecular chirality. Angew Chem Int Ed Engl 1956;5:385-415.

Conceição MJ, Coelho L. Caudal anaesthesia with $0,375 \%$ ropivacaine or 0,375\% bupivacaine in paediatric patients. Br J Anaesth 1998;80:507-8.

Conceição MJ, Coelho L, Khalil M. Ropivacaine 0,25\% compared with bupivacaine $0,25 \%$ by the caudal route. Paediatr Anaesth 1999;9:22933.

Cook B, Grubb DJ, Aldridge LA, Doyle E. Comparison of the effects of adrenaline, clonidine and ketamine on the duration of caudal analgesia produced by bupivacaine in children. Br J Anaesth 1995;75:698-701.

Cortês CAF, Oliveira AS, Castro LFL, Cavalcanti FS, Serafim MM, Taia C, Taia Filho S. Estudo comparativo entre a bupivacaína a $0,5 \%$, mistura enantiomérica de bupivacaína (S75R25) a $0,5 \%$ e ropivacaína a $0,75 \%$ associadas ao fentanil em anestesia peridural para cesarianas. Rev Bras Anestesiol 2003;53:177-87. 
Dalens B. Regional anesthesia in children. Anesth Analg 1989;68:654-72.

Dalens B. Caudal anesthesia. In: Dalens B, editor. Pediatric regional anesthesia. Boca Raton (FL); CRC Press; 1990:353-74.

De Beer DAH, Thomas ML. Review article. Caudal additives in childrensolutions or problems? Br J Anaesth 2003;90:487-98.

De Mey JC, Strobbet J, Poelaert J, Hoebeke P, Mortier E. The influence of sufentanil and/or clonidine on the duration of analgesia after a caudal block for hypospadias repair surgery in children. Eur $\boldsymbol{J}$ Anaesthesiol 2000;17:379-82.

De Negri P, Ivani G, Visconti C, de Vivo P. How to prolong postoperative analgesia after caudal anaesthesia with ropivacaine in children: Sketamine versus clonidine. Paediatr Anaesth 2001;11:679-83.

De Negri P, Ivani G, Tirri T, Modano P, Reato C, Eksborg S, Lonnqvist PA. A comparison of epidural bupivacaine, levobupivacaine, and ropivacaine on postoperative analgesia and motor blockade. Anesth Analg 2004;99:458.

Delfino J, Vale NB. Bupivacaína levógira a 0,5\% pura versus mistura enantiomérica de bupivacaína (S75R25) a 0,5\% em anestesia peridural para cirurgia de varizes. Rev Bras Anestesiol 2001;51:474-82.

Diaz LK, Cantu F. Hemodynamic response to caudal epidural clonidine in a pediatric cardiac patient. Anesth Analg 2003;96:88-90.

Ecoffey C, Desparmet J, Berdeaux A, Giudicelli JF, Saint-Maurice C. Bupivacaine in children: pharmacokinetics following caudal anesthesia. Anesthesiology 1985;63:447-8. 
Fellmann C, Gerber AC, Weiss M. Apnoea in a former preterm infant after caudal bupivacaine with clonidine for inguinal herniorrhaphy. Paediatr Anaesth 2002;12:637-40.

Ferreira FMC. Importância da estereoisometria na atividade bloqueadora neuronal: estudo experimental com anestésicos locais em nervo ciático de rato. Tese apresentada para obtenção de título de Mestre em Medicina à Faculdade de Medicina da Universidade de São Paulo, 1999.

Flacke JW, Bloor BC, Flacke WE. Reduced narcotic requirement by clonidine with improved hemodynamic and adrenergic stability in patients undergoing bypass surgery. Anesthesiology 1987;67:11-9.

Freid EB, Bailey AG, Valley RD. Electrocardiographic and hemodynamic changes associated with unintentional intravascular injection of bupivacaine with epinephrine in infants. Anesthesiology 1993;79:394-8.

Graf BM, Abraham I, Eberbach N, Kunst G, Stowe DF, Martin E. Differences in cardiotoxicity of bupivacaine and ropivacaine are the result of physicochemical and stereoselective properties. Anesthesiology 2002; 96:1427-34.

Groban L, Deal DD, Vernon JC, James RL, Butterworth J. Cardiac resuscitation after incremental overdose with lidocaine, bupivacaine, levobupivacaine, and ropivacaine in anesthetized dogs. Anesth Analg 2001;92:37-43.

Gunter, JB. Benefit and risks of local anesthetics in infants and children. Pediatric Drugs 2002;4:649-72. 
Hackmann T, Friesen M, Allen S, Precious DS. Clonidine facilitates controlled hypotension in adolescent children. Anesth Analg 2003;96: 976-81.

Hannallah RS, Broadman LM, Belman AB, Abramowitz MD, Epstein BS. Comparison of caudal and ilioinguinal/iliohypogastric nerve blocks for control of post-orchipexy pain in pediatric ambulatory surgery. Anesthesiology 1987;6:832-4.

Hoefke W. Clonidine. Pharmacology of antihypertensive drugs, edited by A Scrabine, Raven Press, New York,1980:55.

Huang YF, Pryor ME, Mather LE, Veering T. Cardiovascular and central nervous system effects of intravenous levobupivacaine in sheep. Anesth Analg 1998;86:797-804.

Hussain AS, Siddiqui MS, Hamdard F, Mayhew JF. Postoperative apnoea in an ex-premature infant, is it only related to clonidine. Paediatr Anaesth 2003;13:741-2.

Imbelloni LE, Beato L. Comparação entre bupivacaína (S50R50) e mistura enantiomérica de bupivacaína (S75R25), ambas isobáricas, a 0,5\% em raquianestesia. Estudo em cirurgias ortopédicas. Rev Bras Anestesiol 2001;51:369-76.

Imbelloni LE, Vieira EM, Beato L, Sperni F. Raquianestesia com a mistura enantiomérica de bupivacaína a $0,5 \%$ isobárica (S75R25) em crianças com idades de 1 a 5 anos para cirurgia ambulatorial. Rev Bras Anestesiol 2002;52:286-93. 
Ivani G, De Negri P. New insights into paediatric regional anaesthesia: new drugs. Curr Opin Anaesthesiol 2001;14:353-7.

Ivani G, De Negri P, Conio A, Amati M, Roero S, Giannone S, Lonnqvist PA. Ropivacaine-clonidine combination for caudal blockade in children. Acta Anaesthesiol Scand 2000;44:446-9.

Ivani G, De Negri P, Conio A, Grossetti R, Vitale P, Vercellino C, Gagliardi F, Eksborg S, Lonnqvist PA. Comparison of racemic bupivacaine, ropivacaine, and levo-bupivacaine for pediatric caudal anesthesia: effects on postoperative analgesia and motor block. Reg Anesth Pain Med 2002; 27:157-61.

Ivani G, De Negri P, Lonnqvist PA, Eksborg S, Mossetti V, Grossetti R, Italiano S, Rosso F, Tonetti F, Codiprieto L. A comparison of three different concentrations of levobupivacaine for caudal block in children. Anesth Analg 2003;97:368-71.

Ivani G, Lampugnani E, Torre MA, Calevo-Maria G, De Negri P, Barrometi F, Messeri A, Calamandrei M, Lonnqvist PA, Morton NS. Comparison of ropivacaine with bupivacaine for paediatric caudal block. $\mathrm{Br} \mathrm{J}$ Anaesth 1998;81:247-8.

Jamali S, Monin S, Begon C, Dubousset A, Ecoffey C. Clonidine in pediatric caudal anesthesia. Anesth Analg 1994;78:663-6.

Joshi W, Connelly NR, Freeman K, Reuben SS. Analgesic effect of clonidine added to bupivacaine $0,125 \%$ in paediatric caudal blockade. Pediatr Anesth 2004;14:483-6.

Kamibayashi T, Maze M. Clinical uses of $\alpha_{2}$-adrenergic agonists. Anesthesiology 2000;93:1345-9. 
Karmakar MK, Aun CS, Wong EL, Wong ASY, Chan SKC, Yeung CK. Ropivacaine undergoes slower systemic absorption from the caudal epidural space in children than bupivacaine. Anesth Analg 2002;94:25965.

Klamt JG, Garcia LV, Stocche RM, Meinberg AC. Epidural infusion of clonidine plus ropivacaine for postoperative analgesia in children undergoing major abdominal surgery. J Clin Anesth 2003;15:510-4.

Klimscha W, Tong C, Eisenach JC. Intrathecal $\alpha_{2}$-adrenergic agonists stimulate acetylcholine and norepinephrine release from spinal cord dorsal horn in sheep. An in vivo microdialysis study. Anesthesiology 1997;87:110-6.

Klimscha W, Chiari A, Michalek-Sauberer A, Wildling E, Lerche A, Lober C, Brinkmann $\mathrm{H}$, Semsro THM. The efficacy and safety of a clonidine/bupivacaine combination in caudal blockade for pediatric hernia repair. Anesth Analg 1998;86:54-61.

Koinig H, Krenn CG, Glaser C, Marhofer P, Wildling E, Brunner M, Wallner T, Grabner C, Klimscha W, Semsro THM. The dose-response of caudal ropivacaine in children. Anesthesiology 1999;90:1339-44.

Kopacz DJ, Allen HW, Thompson GE. A comparison of epidural levobupivacaine $0,75 \%$ with racemic bupivacaine for lower abdominal surgery. Anesth Analg 2000;90:642-8.

Krane EJ. Delayed respiratory depression in a child after caudal epidural morphine. Anesth Analg 1988;67:79-82.

Kulka PJ, Bressem M, Tryba M. Clonidine prevents sevoflurane-induced agitation in children. Anesth Analg 2001;93:335-338. 
Lawhead RG, Blaxall HS, Bylund DB. Alpha-2A is the predominant alpha-2 adrenergic receptor subtype in human spinal cord. Anesthesiology 1992; 77:983-91.

Locatelli B, Ingelmo P, Sonzogni V, Zanella A, Gatti V, Spotti A, Di Marco S, Fumagalli R. Randomized, double-blind, phase III, controlled trial comparing levobupivacaine $0.25 \%$, ropivacaine $0.25 \%$ and bupivacaine $0.25 \%$ by the caudal route in children. Br J Anaesth 2005;94:366-71.

Luz G, Innerhofer P, Haussler B, Oswald E, Salner E, Sparr H. Comparison of ropivacaine $0,1 \%$ and $0,2 \%$ with bupivacaine $0,2 \%$ for single-shot caudal anaesthesia in children. Paediatr Anaesth 2000;10:499-504.

Mazoit JX, Dalens BJ. Pharmacokinetics of local anaesthetics in infants and children. Clin Pharmacokinet 2004;43:17-32.

Mikawa K, Maekawa N, Nishina K, Takao Y, Yaku H, Obara H. Efficacy of oral clonidine premedication in children. Anesthesiology 1993;79:926-31.

Motsch J, Böttiger BW, Bach A, Böhrer H, Skoberne T, Martin E. Caudal clonidine and bupivacaine for combined epidural and general anaesthesia in children. Acta Anaesthesiol Scand 1997;41:877-83.

Nau C, Strichartz GR. Drug chirality in anesthesia. Anesthesiology 2002;97: 497-502.

Neter J, Wasserman W, Kutner MH. Applied linear statistical models, Irwin, Massachusetts, $3^{\text {rd }}$ Edition, 1990. p.124-8.

Nishina K, Mikawa K. Clonidine in paediatric anaesthesia. Curr Opin Anaesthesiol 2002;15:309-16. 
Nishina K, Mikawa K, Shiga M, Obara H. Clonidine in paediatric anaesthesia. Paediatr Anaesth 1999;9:187-202.

Pullerits J, Holzman RS. Pediatric neuraxial blockade. J Clin Anesth 1993; 5:342-54.

Rice LJ. Regional anesthesia and analgesia. In: Smith's Anesthesia for Infants and Children. Ed. Motoyama EK, Davis PJ, $6^{\text {th }}$ ed. St. Louis, Missouri; Mosby-Year Book, Inc.1996:425.

Rosner B. Fundamentals of biostatistics, PWS Publishers, Massachusetts, 2nd Edition, 1986a p.326-32.

Rosner, B. Fundamentals of biostatistics, PWS Publishers, Massachusetts, 2nd Edition, 1986b p.442-80.

Rosner B. Fundamentals of biostatistics, PWS Publishers, Massachusetts, 2nd Edition, 1986c p.467-72.

Sharpe P, Klein JR, Thompson JP, Rushman SC, Sherwin J Wandless JG, Fell D. Analgesia for circumcision in a paediatric population: comparison of caudal bupivacaine alone with bupivacaine plus two doses of clonidine. Paediatric Anaesth 2001;11:695-700.

Simonetti MPB, Bird RA. Evaluation of new local anesthetics obtained through the manipulation of the enantiomeric ratio of bupivacaine on the central nervous system of the rat. The Int Monitor, 2000;12:129.

Simonetti MPB, Fernandes L. S(-) bupivacaine and RS ( \pm ) bupivacaine: a comparison of effects on right and left atria of the rat [abstract]. Reg Anesth 1997;22(suppl):58. 
Simonetti MPB, Ferreira FMC. Does the D-isomer of bupivacaine contribute to the improvement of efficacy in neural block? Reg Anaesth Pain Med 1999;24(suppl):43.

Simonetti MPB, Ferreira Jr. R, Bird RA. Optimization of the therapeutic index of bupivacaine through the manipulation of the enantiomeric ratio. WCA 2000 Book of Abstracts, 2000:247(P6.4.05).

Simonetti MPB, Valinetti EA, Ferreira FMC. Clonidina: de descongestionante nasal a analgésico potente. Considerações históricas e farmacológicas. Rev Bras Anestesiol 1997a;47:37-47.

Simonetti MPB, Valinetti EA, Ferreira FMC. Avaliação da atividade anestésica local da S(-) bupivacaína: estudo experimental in vivo no nervo ciático de rato. Rev Bras Anestesiol 1997b;47:425-34.

Smith MS, Schambra UB, Wilson KH, Page SO, Hulette C, Light AR, Schwinn DA. Alpha-2 adrenergic receptors in human spinal cord: specific localized expression of mRNA encoding alpha-2 adrenergic receptor subtypes at four distinct levels. Brain Res Mol Brain Res 1995;34:109-17.

Tanaka PP, Souza RO, Salvallaggio MFO, Tanaka MAA. Estudo comparativo entre a bupivacaína (S75R25) a 0,5\% em anestesia peridural em pacientes submetidos a cirurgia ortopédica de membros inferiores. Rev Bras Anestesiol 2003;53:331-7.

Taylor R, Eyres R, Chalkiadis GA, Austin S. Efficacy and safety of caudal injection of levobupivacaine $0,25 \%$, in children under 2 years of age undergoing inguinal hernia repair, circumcision or orchidopexy. Paediatr Anaesth 2003;13:114-21.

Timm NH. Multivariate analysis with applications in educations and psychology.Belmont: Wadsworth Publishing Company, 1975. p.444-71. 
Valenzuela C, Snyders DJ, Bennett PB, Tamargo J, Hondeghem LM. Stereoselective block of cardiac sodium channels by bupivacaine in guinea pig ventricular myocytes. Circulation 1995;92:3014-24.

Valinetti EA. Clonidina/Anestésicos Locais no Nervo Periférico de Rato. Tese apresentada para obtenção de Título de Mestre em Medicina a Faculdade Medicina Universidade São Paulo, 1995.

Velhote MCP. Afecções cirúrgicas da região inguinal. In: Maksoud JG. Cirurgia Pediátrica. 2ed., Rio de Janeiro; Revinter; 2003. p.711-16. 
ANEXOS 


\section{ANEXO 1}

\section{Consentimento Pós- Informado}

É procedimento de rotina a anestesia combinada (geral e epidural sacra) em crianças que se submetem a cirurgias para correção de hémia inguinal, umbilical, testículos ectópicos, varicocele, hidrocele e hipospádia. Este estudo avaliará aleatoriamente a combinação de anestésicos locais com um agente chamado clonidina.

A clonidina quando associada a anestésicos locais apresenta as seguintes vantagens descritas em estudos anteriores com a bupivacaína racêmica, mas não estudado com a bupivacaína levógira: 1. maior duração do bloqueio sensitivo, 2. menor consumo de drogas anestésicas e analgésicas no intra operatório, 3. melhor estabilidade hemodinâmica, 4. analgesia no pós- operatório. Todas essas vantagens podem ser obtidas com opióides, porém, estes agentes apresentam efeitos colaterais importantes, como retenção urinária, prunido, náuseas e vômitos, e depressão respiratória. A depressão respiratória é o efeito colateral mais temido, porque impõe risco de vida ao paciente. A clonidina será utilizada no lugar dos opióides no intuito de obter tais vantagens.

Por se tratar de técnica anestésica rotineiramente utilizada o estudo apresenta riscos mínimos inerentes à técnicajá consagrada para estes procedimentos cirúrgicos.

A Instituição proverá o tratamento da patologia em questão caso não haja consentimento para participar do estudo, ou abandone o estudo sem prejuízo para o paciente. A Instituição se compromete a formecer toda estrutura para o tratamento de intercorrências que houver durante o estudo, como sempre o faz à todos os pacientes. Após ter lido, compreendido, redimido todas as dúvidas sobre o estudo, assinarei o documento que concorda com a participação de no estudo.

São Paulo de 200

Nome 


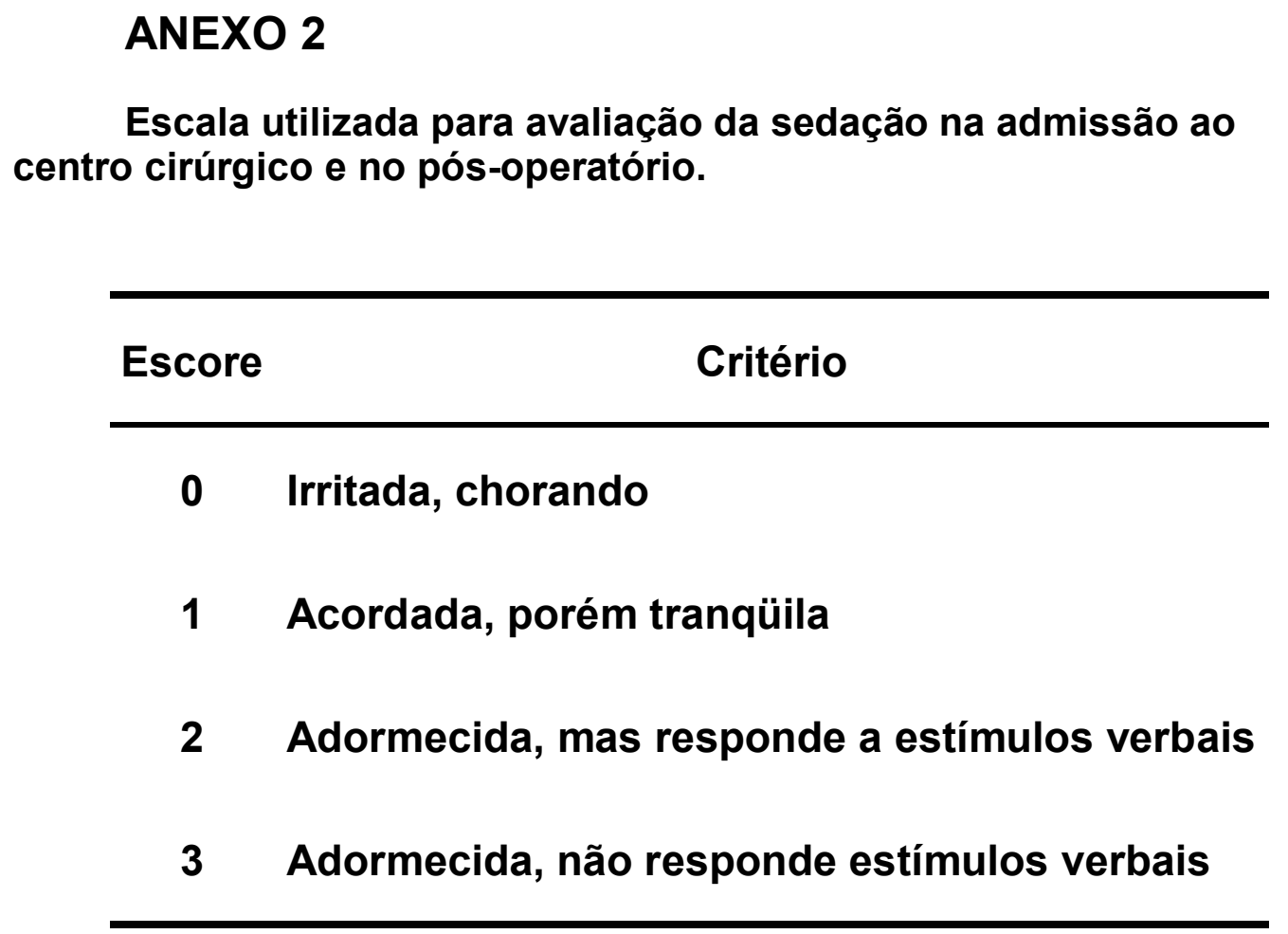




\section{ANEXO 3}

Fórmula para cálculo da concentração de sevoflurano

C\%= FB. PVA. 100/ FT.( Patm - PVA)

onde:

C\% - concentração do halogenado

FB - fluxo de vaporização da câmara ( L/min)

PVA - pressão de vapor do anestésico

FT - fluxo total ( $\mathrm{L} / \mathrm{min})$ 


\section{ANEXO 4}

\section{Escala para avaliação do bloqueio motor (Bromage, 1969)}

\begin{tabular}{cc}
\hline Escore & Critério de avaliação \\
\hline zero & Movimenta ambos membros inferiores \\
1 & Dobra joelho, movimenta os pés \\
2 & Movimenta apenas o pé, não dobra joelho \\
3 & Não movimenta os membros inferiores \\
\hline
\end{tabular}




\section{ANEXO 5}

\section{Escala (OPS) para avaliação da dor pós-operatória.}

Parâmetros, critério, escores (Hannallah, 1987)

\section{Critério}

Escore $1 \mathrm{~h} 2 \mathrm{~h} 4 \mathrm{~h} 6 \mathrm{~h} 8 \mathrm{~h}$

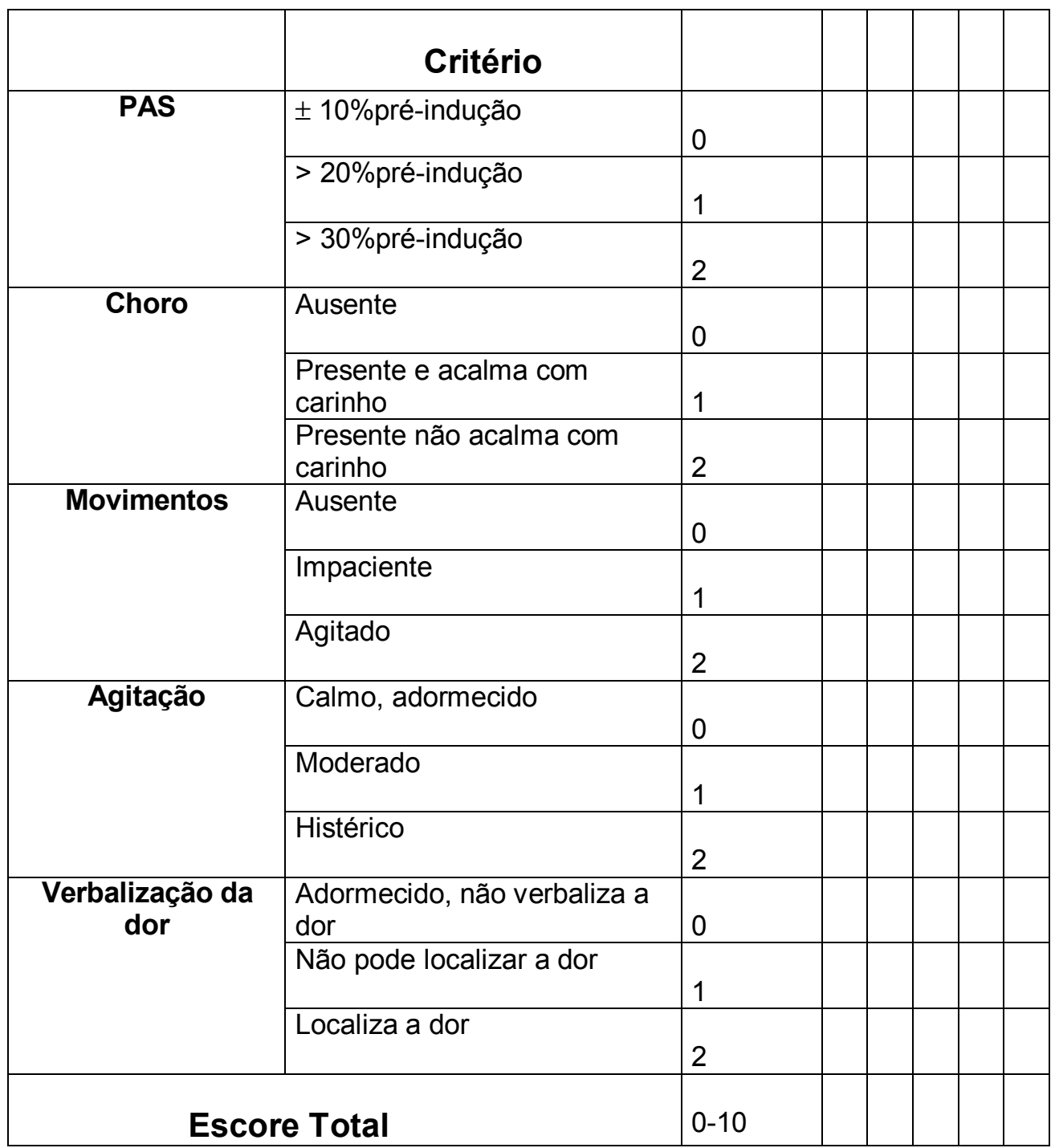




\section{ANEXO 6}

\section{Ficha de coleta de dados}

Nome:

Peso

Idade:

Altura:

RG HC

Tipo de cirúrgia

MPA: Midazolam - Dose

mg Horário Admnistração

Início Anestesia:

Horário IOT:

Indução: Venosa: Inal:

Manut:

Horário bloqueio:

Tipo:

A.Local:

$\%$ A Local:

Vol. Anest.local

Adjuvante/dose:

Horário incisão pele: Hor.fim cirurgia:

Tempo Indução até IOT: Tempo Indução até extubação:

Tempo Bloqueio até incisão pele:

Hor.despertar: Horário extubação:

\begin{tabular}{|c|c|c|c|}
\hline critério & escore & admissão & despertar \\
\hline $\begin{array}{c}\text { Sem sedação, } \\
\text { irritada, chorando }\end{array}$ & 0 & & \\
\hline $\begin{array}{c}\text { Acordada, porém } \\
\text { tranquila }\end{array}$ & 1 & & \\
\hline $\begin{array}{c}\text { Sonolenta, } \\
\text { responde estímulo } \\
\text { verbal }\end{array}$ & 2 & & \\
\hline $\begin{array}{c}\text { Sonolenta, não } \\
\text { responde estímulo } \\
\text { verbal }\end{array}$ & 3 & & \\
\hline
\end{tabular}


Parâmetros Hemodinâmicos: fluxo total 4I/ min ( oxig/ óxido nitroso)

\begin{tabular}{|l|l|l|l|l|l|l|l|}
\hline & PAS & PAD & PAM & FC & $\mathbf{S p O}_{2}$ & $\begin{array}{l}\text { Fluxo } \\
\text { vap. }\end{array}$ & $\mathrm{EtCO}_{2}$ \\
\hline $\begin{array}{l}\text { Antes } \\
\text { indução }\end{array}$ & & & & & & & $-\cdots$ \\
\hline Indução & & & & & & & ------- \\
\hline IOT & & & & & & & ----- \\
\hline $\begin{array}{l}\text { Após } \\
\text { IOT }\end{array}$ & & & & & & & \\
\hline
\end{tabular}

Consumo de anestésicos: Tipo / Indução / Manutenção/ Total/ Variação fluxo ou \% anestésico inalatório na indução-IOT e procedimento(total)

\begin{tabular}{|c|c|c|c|c|c|}
\hline Tipo * & Indução & Manutenção & Total & $\begin{array}{l}\text { \% ou fluxo } \\
\text { câmara } \\
\text { vaporização } \\
\text { até IOT }\end{array}$ & $\begin{array}{l}\text { \% ou fluxo } \\
\text { câmara } \\
\text { vaporização } \\
\text { durante todo } \\
\text { procedimento }\end{array}$ \\
\hline Sevo & & & & & \\
\hline Propofol & & & & & \\
\hline
\end{tabular}

*Anotar o anestésico utilizado na INDUÇÃO/ MANUTENÇÃO de acordo com o protocolo 
Parâmetros Hemodinâmicos durante procedimento cada 5' após IOT

\begin{tabular}{|c|c|c|c|c|c|c|c|}
\hline Horário & PAS & PAD & PAM & FC & $\mathrm{SpO}_{2}$ & $\begin{array}{c}\text { Fluxo } \\
\text { câmara ou \% }\end{array}$ & $\mathrm{EtCO}_{2}$ \\
\hline \multicolumn{8}{|l|}{$5^{\prime}$} \\
\hline \multicolumn{8}{|l|}{$10^{\prime}$} \\
\hline \multicolumn{8}{|l|}{$15^{\prime}$} \\
\hline \multicolumn{8}{|l|}{$20^{\prime}$} \\
\hline \multicolumn{8}{|l|}{$25^{\prime}$} \\
\hline \multicolumn{8}{|l|}{$30^{\prime}$} \\
\hline \multicolumn{8}{|l|}{$35^{\prime}$} \\
\hline \multicolumn{8}{|l|}{$40^{\prime}$} \\
\hline \multicolumn{8}{|l|}{$45^{\prime}$} \\
\hline \multicolumn{8}{|l|}{$50^{\prime}$} \\
\hline \multicolumn{8}{|l|}{$55^{\prime}$} \\
\hline \multicolumn{8}{|l|}{$60^{\prime}$} \\
\hline \multicolumn{8}{|l|}{$65^{\prime}$} \\
\hline \multicolumn{8}{|l|}{$70^{\prime}$} \\
\hline \multicolumn{8}{|l|}{$75^{\prime}$} \\
\hline \multicolumn{8}{|l|}{$80^{\prime}$} \\
\hline \multicolumn{8}{|l|}{$85^{\prime}$} \\
\hline \multicolumn{8}{|l|}{$90^{\prime}$} \\
\hline \multicolumn{8}{|l|}{$95^{\prime}$} \\
\hline \multicolumn{8}{|l|}{$100^{\prime}$} \\
\hline \multicolumn{8}{|l|}{$105^{\prime}$} \\
\hline \multicolumn{8}{|l|}{$110^{\prime}$} \\
\hline \multicolumn{8}{|l|}{$115^{\prime}$} \\
\hline \multicolumn{8}{|l|}{$120^{\prime}$} \\
\hline \multicolumn{8}{|l|}{$125^{\prime}$} \\
\hline \multicolumn{8}{|l|}{$130^{\prime}$} \\
\hline \multicolumn{8}{|l|}{$135^{\prime}$} \\
\hline \multicolumn{8}{|l|}{$140^{\prime}$} \\
\hline $145^{\prime}$ & & & & & & & \\
\hline
\end{tabular}

Uso de Analgésicos no pós-operatório (solicitado ou escala OPS $\geq 6$ )

\begin{tabular}{|l|l|l|l|l|}
\hline Medicação & Por solicitação & $\begin{array}{c}\text { Pela escala } \\
\text { OPS }\end{array}$ & Dose & Horário \\
\hline & & & & \\
\hline & & & & \\
\hline & & & & \\
\hline & & & & \\
\hline & & & & \\
\hline
\end{tabular}


